Harrison, S. Adolphs, A., Gillon-Dowens, M., Du, P. \& J. Littlemore (2018). All hands on deck. Negotiation over gesture forms in collaborative discourse. Lingua 207, 1-22. https://doi.org/10.1016/j.lingua.2018.02.002

\title{
All hands on deck. Negotiation over gesture forms in collaborative discourse
}

Simon Harrison, University of Nottingham Ningbo China

Svenja Adolphs, University of Nottingham

Margaret Gillon-Dowens, University of Nottingham Ningbo China

Ping Du, University of Nottingham Ningbo China

Jeannette Littlemore, University of Birmingham

\begin{abstract}
Language Related Episodes occur when speakers explicitly question lexical and grammatical aspects of the language they are using, resulting in collaborative discourse and assisted performance from peers. This paper demonstrates how such negotiation and repair may occur in relation to the gestural component of a speaker's expression, leading us to introduce the parallel term 'Gesture Related Episodes'. Our single case analysis reveals a range of issues that have received little attention, including the problems that people experience with gestures, what constitutes struggling in the gestural modality, and how people help each other to gesture more effectively in collaborative discourse. Our discussion links these issues to the L2 concerns and knowledge asymmetries in our data, as well as to conceptual and conventional features of gestures more generally.
\end{abstract}

Keywords: Language Related Episodes, Gestures, Collaborative discourse, L1-L2 interaction, Assisted Performance, Peer dialogue

\section{Introduction}

In research on Second Language Acquisition, the concept of a 'Language Related Episode' or 'LRE' was defined by Swain and Lapkin (1998) as “any part of a dialogue where the students talk about the language they are producing, question their language use, or correct themselves or others" (p. 326). To exemplify 'questioning language use' and 'correcting each other', Leeser (2004) specifies that 'LREs include instances in which learners may (a) question the meaning of a linguistic item; (b) question the correctness of the spelling/pronunciation of a word; (c) question the correctness of a grammatical form; or (d) implicitly or explicitly correct their own or another's usage of a word, form or structure" (p. 56).

According to a review of research into L2 peer dialogue by Swain et al. (2002), LREs constitute critical moments in interaction. They trigger episodes of "metatalk" within which students help each other to "solve linguistic problems and or co- 
construct language or knowledge about language" (Swain et al. 2002: 172; Ohta 2001). How students use gesture - visible bodily action as utterance (Kendon 2004) in the process of solving linguistic problems and co-constructing knowledge is well understood (McCafferty 2002; Mori and Hayashi 2006; Smotrova and Lantolf 2013; Smotrova 2014; Debras, Horgues and Scheuer 2015). Smotrova's (2014) study of gesture during L2 group discussions of lexical items, for example, showed that students deployed gesture "to externalize their understandings of word meanings and make them accessible to their peers" (p. 390). Despite the recognition that gesture is central to L2 interaction and second language acquisition, the word 'language' in the term 'Language Related Episode' has been used exclusively to denote the problems that can occur with the verbal component of a linguistic expression (i.e. pronunciation, spelling, lexis and grammar).

In this paper, we illustrate how an episode of collaborative dialogue can occur to solve not only a verbal problem but also a gestural problem. The genesis of the collaboration that we will present is focused on the form and function of gestures to an extent that we believe warrants introducing the parallel term, 'Gesture Related Episode'. Thus to paraphrase Swain and Lapkin's quote above, a Gesture Related Episode would constitute "any part of a dialogue where the students talk about the gesture they are producing, question their gesture use, or correct their own or others' gestures" (italicised words exchanged). As we will show, studying a Gesture Related Episode allows us to identify a range of issues that have received less attention in the fields of language learning and L2 interaction. These include the problems that people experience with gestures, what constitutes struggling in the gestural modality, and how people help each other to gesture more effectively in interaction. Since gestural practices observed in L2 interaction are often also found in L1 interaction (e.g. Olsher 2004), our description of Gesture Related Episodes should help understand gesture in interaction more generally.

\subsection{Background}

The term 'Language Related Episodes' has been used to designate instances in L2 interaction when students struggle, make mistakes, or otherwise orient explicitly to verbal features of their linguistic production (Swain 1998; Swain and Lapkin 1998). This concept was illustrated by Swain and Lapkin (1998), who examined "the dialogue that occurs between two learners as they attempt to solve the linguistic problems they face while writing a short narrative" (p. 321). What the researchers called Language Related Episodes occurred when these two learners, who were studying French, explicitly oriented to lexical choice or other aspects of L2 form: "The lexis-based LREs involved students seeking French vocabulary or choosing among competing French vocabulary items. The form-based LREs involved students focusing on spelling or an aspect of French morphology, syntax, or discourse" ( $p$. 326). According to the researchers, such LREs illustrated for these learners the "ways 
in which their language use serves as a tool supporting L2 learning by consciously singling out the L2 as an object to be monitored, reflected upon, and manipulated" (Swain and Lapkin 1998: 329).

Subsequent research into Language Related Episodes has developed distinctions between different types of LREs (Williams 1999), has documented the different outcomes of LREs (Swain 1998), and has evaluated the factors that affect their frequency and outcome, such as proficiency of group members (Leeser 2004) and configuration of the groups (Edstrom 2015). To develop distinctions between different types of LREs, Williams (1999) collected sixty-five hours of audio data from eight adult language learners on an intensive English program over the course of an eight-week study. For the current research, the most relevant category observed by Williams was called 'negotiation over a language item' (p. 596). This was defined as "those exchanges containing clear evidence of communicative breakdown followed by an attempt to jointly reconstruct meaning" (p. 598). The evidence of breakdown in Williams' study included not only lexis and grammar but also, for example, "nontarget-like pronunciation" (p. 598). Three main outcomes of such LREs are commonly identified. LREs may be "solved correctly..., left unresolved or abandoned..., (or) resolved incorrectly" (Leeser 2004: 65-66; Swain 1998).

When collaborating to resolve Language Related Episodes, students offer each other various forms of assistance (Ohta 2001; Alçon Soler 2002; Zeng and Tkatsuka 2009). Ohta's (2001) longitudinal study of learners of Japanese, for example, distinguished between the forms of assistance that students offered during two main categories of LREs, namely, when a speaker began to struggle and when a speaker began to make mistakes. When the speaker struggled, students helped each other by waiting, prompting, co-constructing, and explaining; when the speaker made mistakes, the peers helped by initiating repair, providing repair, or asking the teacher (Ohta 2001: 89). Struggling and making mistakes in Ohta's study often occurred because students were cognitively "absorbed by the demands of production" in the L2 (p. 80). The speaker's peers, on the other hand, were cognitively and attentionally free to 'map along' with the speaker's utterance, 'notice' where help may be needed, 'project' what linguistic elements could be appropriate, and 'chime in' with a relevant linguistic expression to assist the speaker (Ohta 2001).

Studies of gesture as the source of a Language Related Episode are lacking, but research into how students use gesture to provide assistance during a Language Related Episode has been building for almost two decades. An important catalyst in this line of research was the experimental evidence that gestures convey aspects of semantic meaning underpinning the speaker's utterance (McNeill 1992). Researchers in Second Language Acquisition have subsequently shown how the meaning expressed through gesture is an important basis in L2 interaction for linguistic understanding and language development (McCafferty 2002; van Compernolle and Williams 2011; Smotrova 2014).

Gesture can play an assistive role as a tool for thinking, and this function has been observed to facilitate spoken discourse in contexts of L2. The use of iconic gestures - gestures whose form shares a resemblance with its referent (McNeill 
1992) - may facilitate the speaker's access to lexical items in the L2 (McCafferty 2002; van Compernolle and Williams 2011; Smotrova 2014). Such iconic gestures may also reflect understanding of grammatical structures that the student is not yet able to enunciate verbally (Lantolf 2010). Gestures may help speakers to self-regulate other aspects of their L2 performance too. 'Beat' gestures, for example, are rhythmic pulsing movements of the hands along with speech (McNeill 1992). Students have been observed to use beat gestures when speaking to help control aspects of L2 intonation, stress, and prosody (McCafferty 2006).

From the perspective of gesture perception, the information that peers (or teachers) perceive when a speaker uses gesture has been shown to determine how those peers evaluate the speaker's understanding and tailor their assistance to the speaker accordingly (Olsher 2004; Mori and Hayashi 2006; Smotrova \& Lantolf 2013). For example, Olsher (2004) documented a specific multimodal practice in L2 interaction called 'embodied completion' that involves speakers "launching a turn at talk, and then at a point where some trajectory of the turn is projectable, ceasing to talk and completing the action that had been initiated by the partial turn through gesture or embodied display" (p. 221). Olsher (2004) stressed that embodied completions were common among L1 speakers as well but illustrated that in L1-L2 interaction the use of such 'hybrid moves' highlighted the L2 speaker's understanding of the target language whilst flagging up potential gaps for peers to assist with (cf. Mori and Hayashi 2006).

Peers may offer assistance verbally or they may use their own gestures as tools to assist a struggling student's performance, such as when they provide a struggling speaker with explicit corrective feedback using either both speech and gesture or with gesture alone (Debras, Horgues and Scheuer 2015). A parallel line of L2 research has shown the centrality of gestures in teaching vocabulary (Smotrova \& Lantolf 2013), pronunciation (Smotrova 2015) and grammar (e.g. tense and aspect; Matsumoto and Mueller Dobs 2017).

Overall, the research on Language Related Episodes in SLA shows that collaborative dialogue between students can arise because of a focus on linguistic (i.e. verbal) form, including pronunciation, spelling, lexical choice, and grammar. During the collaborative dialogue that ensues from a Language Related Episode, students offer each other various forms of assistance to resolve such episodes, which importantly include gesture. Though gesture in L2 interaction should not be viewed as merely compensatory (Gullberg 2013), the rhythmic quality of beats helps regulate aspects of verbal performance in the L 2 and the imagery provided by iconic gestures facilitates access to meaning for both speakers and peers when they collaborate to solve linguistic issues. Beats and iconics combine with broader multimodal practices like 'embodied completions' to facilitate interaction between speakers from different backgrounds. Importantly, these interactive functions of gestures have been observed outside of SLA research, where the assistive role of gesture in collaborative discourse is similarly well-documented in contexts of group scientific reasoning (Williams, 2011), collective remembering (Cienki, Bietti and Kok, 2014), and other forms of situated instructional activity (Arnold 2012; Hazel 2014). 
However, what has not yet been described in this body of research is the parallel situation to LREs, where the breakdown and ensuing collaborative repair in communication are predominantly gesture-related, rather than language-related (i.e. 'verbal-related'). Though we acknowledge that collaborative discourse usually always involves multiple multimodal utterances (Hutchins \& Numura 2011: 29), we propose that the term 'Gesture Related Episode' helps single out situations where collaborative repair occurs in relation to the speaker's gesture - people visibly struggling with gestures, at which point their peers help them to gesture more effectively. To demonstrate the need for this distinction, our paper uses a single case analysis (Mondada 2011a) to describe the occurrence, negotiation, and resolution of a focus on gesture form during a discussion in English between a group of international university students. Through a micro-analysis of the video-recorded interaction, we aim to answer the following research questions: What constitutes 'struggling' or 'making mistakes' in the gestural modality? How might a gesture become 'consciously singled out' as an object of critical scrutiny? What might negotiation over a 'gesture item' look like? How might peers assist a speaker experiencing problems with her gestures?

\section{Methodology}

\subsection{The single case analysis}

Gesture Related Episodes occur in collaborative discourse over extended interactive sequences and develop thorough a number of stages: (1) Initial struggling and breakdown, (2) Collaboration and assistance, (3) Co-construction, and (4) Resolution. Each of these stages involves several turns of talk which must be micro-analysed on the level of speech and gestures in order to understand how and why the participants orient to a focus on gesture form. A suitable method to introduce this interactive practice is therefore the 'single case analysis', which according to Mondada (2011a) "allows for an analysis of the systematic distribution of (...) linguistic resources within the talk and how they change over time" (p. 31).

\subsection{Corpus and data selection}

Our case is taken from a corpus of three interactions lasting 45-60 minutes each between Chinese students and international students of other nationalities, filmed in Spring 2015 at the campus coffee shop of a British university in China with the broad goal of collecting samples of collaborative dialogue. In one case, the students had met to discuss their homework without intervention from the researchers, while in the other two cases, the students had been convened by the researchers who also allocated them a discussion task. All participants were aged between 21 and 28 years old. The study was approved by the university ethics committee and all participants gave informed consent to be audio- and video-recorded (aware of the possibility of appearing un-masked in future publications). The specific focus on gesture was not revealed to the participants. 
The interaction we have selected to illustrate a Gesture Related Episode involves three female Chinese students (Bai, Li, and Chen) and a male student from the USA (Mike; all pseudonyms). Bai, Li, and Chen were in their final year of a Bachelor's degree program in either English and Applied Linguistics or English and International Business, while Mike was on an MA program in Applied Linguistics and English Language Teaching. Mike was recruited by one of the authors who asked his current MA students for volunteers to discuss their proposal for dissertation research with upper level undergraduates on the Applied Linguistics program. Bai, $\mathrm{Li}$, and Chen were recruited at the same university from an undergraduate course that offered credit for research participation, and they were informed they would be meeting with an MA student in their capacity to offer feedback on a research proposal in Applied Linguistics. We acknowledge, therefore, that this interaction was not 'naturallyoccurring'; however, the kind of interaction we have filmed can occur spontaneously in this international context too.

The meeting took place around a table situated on the veranda of the campus coffee shop; the chairs were pre-arranged to allow optimal vantage point for a camera but participants chose where to sit spontaneously on arrival; and an audio-recorder was placed in the middle of the table (Fig. 1). We left the camera unmanned during the interaction to reduce any pressure from the presence of a researcher, then returned forty-five minutes later, at which point the interaction began to wrap up.

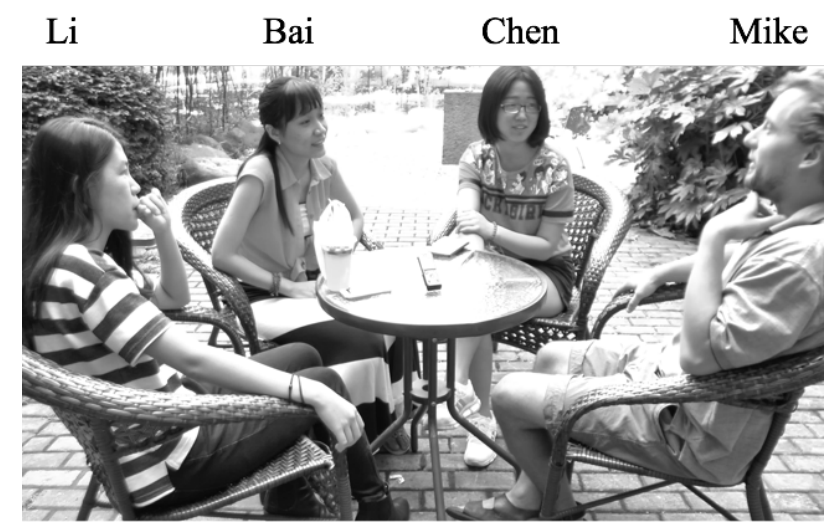

Fig. 1. Interaction set-up and pseudonyms of participants

Within this interaction, the Gesture Related Episode (i.e. a type of Language Related Episode in which the interactants focus not on verbal elements as traditionally described but on gestural elements) occurred when the American student asked the Chinese students a question about local geography. One of the students took the lead in answering this question but quickly ran into difficulty. Recalling William's (1999) category of LRE's, this specific episode would be categorized as 'negotiation over a language item'. However, the language item was not a verbal item, such as would concern lexis or grammar; it was a gestural item. As with the verbal-focused LRE's that have been described, what we are calling a 'Gesture Related Episode' also led to 
"communicative breakdown followed by an attempt to jointly reconstruct meaning" (William's 1999: 598).

\subsection{Data transcription}

To transcribe speech, we adapted relevant notation conventions from conversation analysis, including interruptions, overlapping speech, laughter, restarts, and pauses (Appendix 1; Jefferson 2004). To analyse gesture during this episode, we followed Kendon's (2004) transcription scheme for coding the temporal organization of gesture in relation to speech in terms of preparation, stroke, hold, and retraction phases; Appendix 1). To describe the form and function of gestures, we combined descriptions of form features (hand shape, location, orientation, movement; Bressem 2013) with descriptions of the gestures in terms of mode of representation, such as drawing, tracing, modeling, and enacting (Müller 2014). Aspects of eye-gaze (such as shifts in eye-gaze direction) are transcribed in a line above the verbal utterance when relevant to the analysis.

In presenting our transcripts in the analysis section, we follow the convention of including frame-grabs from relevant moments in the video feed, anchored in the transcript with a hashtag. In order to capture different gestures happening at the same time, the figures often juxtapose two screen shots of the same moment of interaction: a wide shot to see aspects of the group configuration and a shot zoomed in on the hands.

\section{Analysis}

Before we analyse how the Gesture Related Episode emerged, developed, and was resolved, it is necessary to specify the kind of gesturing on which it was based. This discussion took place in Ningbo, a city in Zhejiang province, and the student's question was about the relative location of the neighboring province Anhui, formulated as follows: "Anhui... where is it from here Zhejiang... or from Ningbo?". In response to the American student's request for the location of Anhui, one of the Chinese students began to illustrate Chinese geography through a 'gestural depiction' (Kendon 2004; Streeck 2009; Müller 2014). According to Kendon (2004), depiction occurs when gesturing hands "engage in a pattern of movement that is recognized as 'creating' an object in the air (p. 160). Depiction can therefore be considered as a kind of 'iconic' gesture (McNeill 1992). Specifically for our speaker, she began using extended index fingers to depict a diagram of the relative locations of local cities and provinces, the tips of the fingers 'drawing' (Müller 2014) a series of circles while uttering place names to illustrate their relative locations ("this is Shanghai, and this is Zhejiang", etc.). Rather than creating this depiction in the air i.e. in 'gesture space' (McNeill 2005), she used the surface of the group's table as a support for her depiction, thus producing what Goodwin (2007) calls 'environmentally-coupled gestures'. By coupling her depiction with the table-top, the speaker used gesture, first to ground, then to elaborate an abstract representation of Chinese geography, creating 
a concrete focal referent for mutual orientation in the ensuing discourse (see also Hutchins 2005; Hazel 2014).

This strategy turned out to be problematic, however. What we are going to analyse as a Gesture Related Episode occurred when this student started to struggle with her gestural depiction. We are going to show how her peers consequently collaborated by using their own speech and gestures to assist her performance until the task was resolved. This episode of collaboration lasts 63 seconds, starting with Mike's question and ending after the resolution when Mike utters a change-of-state token and shifts to a new topic. After the posing of the question (14 seconds), the analysis of this episode is divided into the different stages it went through: (i) Initial response to the question, struggling, and communication breakdown (12 seconds), (ii) Collaborative dialogue and assisted performance (10 seconds), (iii) Co-construction (15 seconds), and (iv) Resolution of the task (12 seconds). For each stage, the verbal and gestural interaction of the group is described, accompanied by excerpts from the transcription and illustrative screenshots.

\subsection{Initial response and communication breakdown}

Bai starts her gestural depiction of local geography by leaning towards the table and using a single index finger to draw three circles on the table (Fig. 2a). She synchronises the drawing of each circle with a verbal utterance that indicates what the circle refers to: "this is Zhejiang and this is Shanghai and Anhui is near here" (line 12, Fig. 2b). After this utterance her peer Chen softly backchannels "uhuh", signifying her agreement and support for the description that Bai has offered (line 3). 
$1 \mathrm{BAI}$ and er for example this is zhejiang and this is \#shanghai | **************************/ $* * * * * * * * * * * * * * * /$ right index traces circle $1 \quad$ circle 2

2 and anhui is near here / $* * * * * * * * * * * * * * * * * * *$

circle 3

$3 \mathrm{CHN} \quad{ }^{\circ} \mathrm{uhuh}^{\circ}$

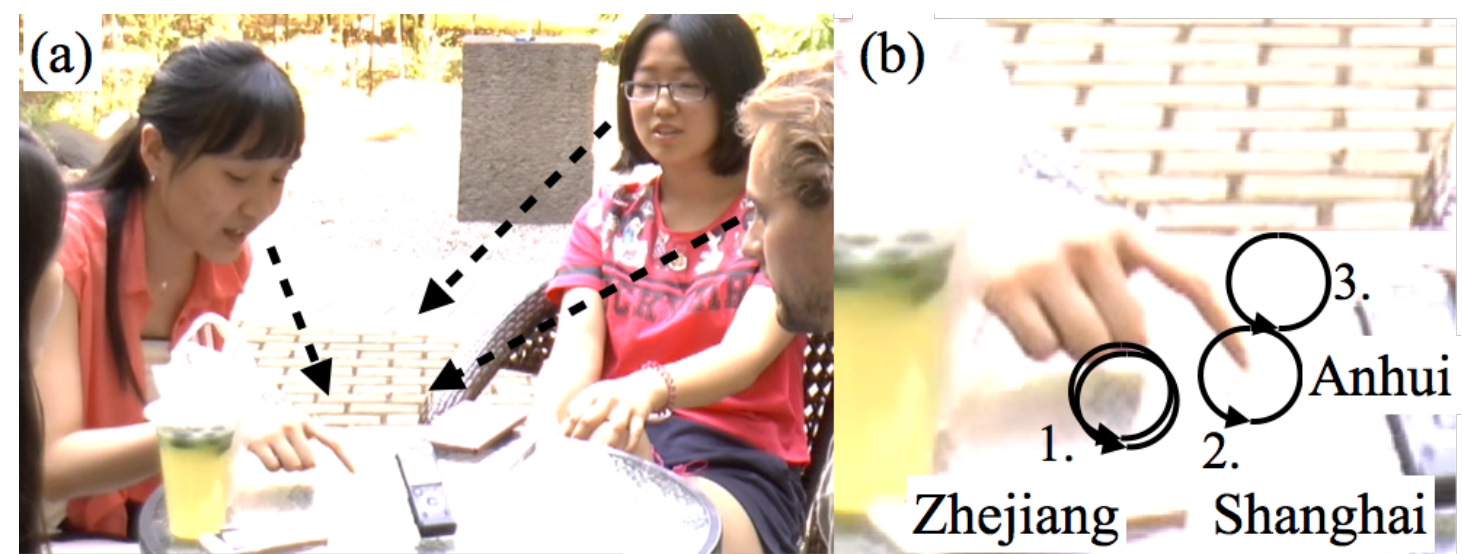

Fig. 2. Index finger outlines three circles for "Zhejiang", "Anhui", and "Shanghai"

Having located the relative positions of Zhejiang, Shanghai, and Anhui, Bai then produces individual deictic i.e. pointing gestures into two of the circles she has just drawn, repeating "and this is Zhejiang" with the first point and "this is Anhui" with the second point (line 4). Each point is produced with the extended index finger of a different hand, and the first point is held during the second point to indicate relative locations (Fig. 3a). As she produces the second point she shifts gaze to Mike, so that she is looking at him as she says "this is Anhui" with both pointing gestures held (see '---->MIK' above the transcription of speech below). This utterance answers Mike's initial question ("where is Anhui?" in relation to their current province Zhejiang). Bai is looking at Mike with this answer, but Mike remains focused on Bai's hands and does not respond (Fig. 3b). 
$>$ MIK

4 BAI and this is zhejiang and this\# is (.) anhui

$(\mathrm{rh}) / \sim$

$* * * * * * * * * * * * * * * * * * * * * * * * * 1$

(lh)

$* * * * * * * * * * * * *$

right finger points to space on right/ left finger points to space on left

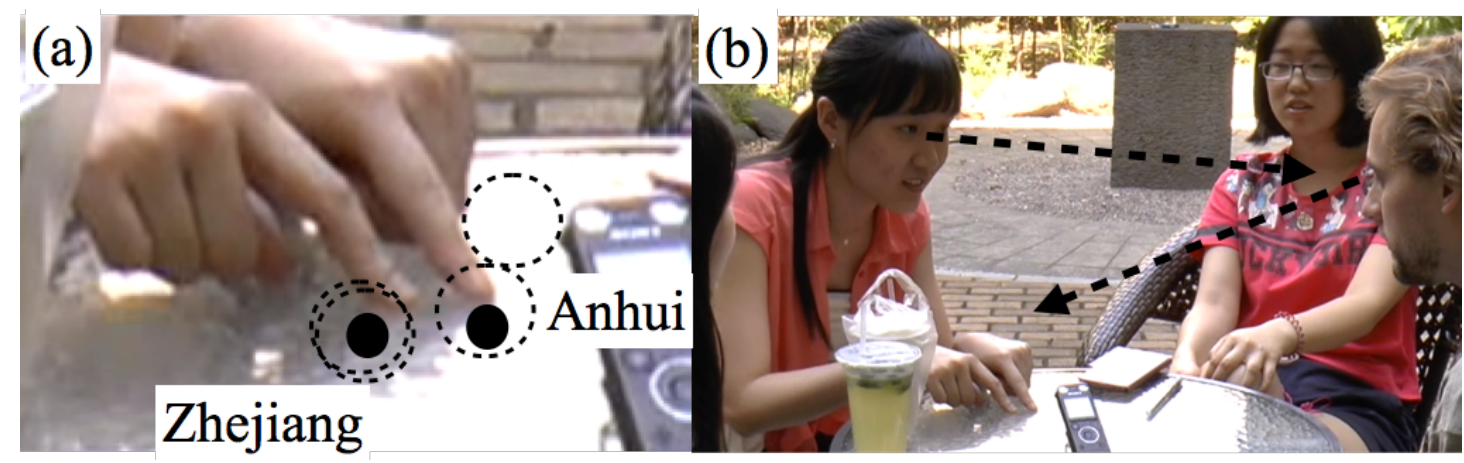

Fig. 3. (a) Index fingers establish relative locations of provinces, (b) Bai shifts gaze to Mike whose gaze remains fixed on her hands

In absence of any feedback from Mike, Bai elaborates on her answer. She now shows that the locations she has just drawn are to be understood as relative locations within the broader geography context of China. To do this, she uses the two extended index fingers to symmetrically trace semi circles that encapsulate the locations she has just designated as 'Zhejiang' and 'Anhui' (Fig. 4). She does this once, saying "and this is the China" (pronounced /t faIni/), pauses momentarily, then performs the same gesture again while repeating "China" (with more standard pronunciation /t fainə/; line 5). 
5 BAI and this\# is the china (.) china (.)

/ ************** $\sim * * * * * *$

both index fingers symmetrically trace semi-circles (repeated)

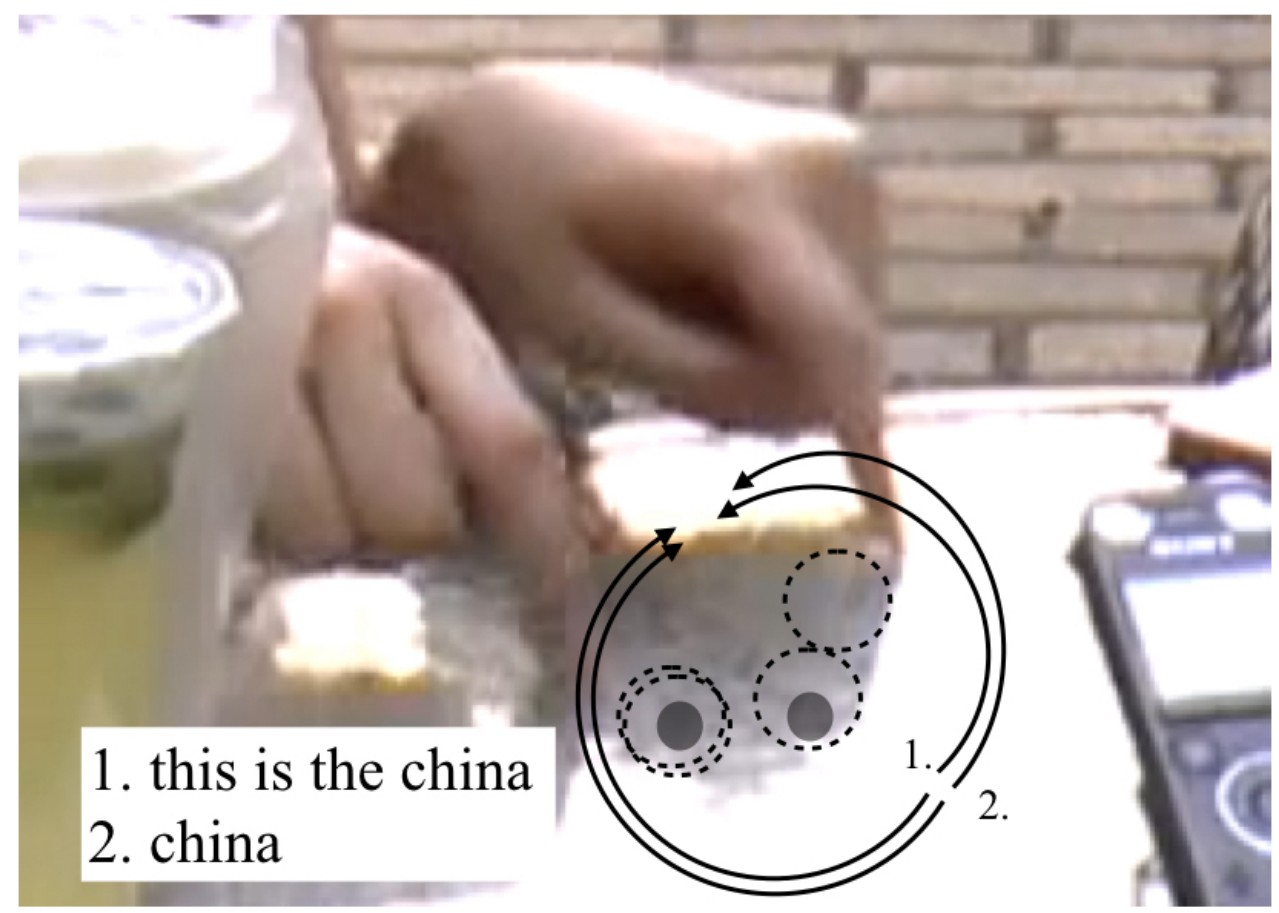

Fig. 4. Both index fingers trace semi-circles around locations as "China"

Immediately after Bai repeats "China", the peer to her right, Li, begins to laugh (line 6). Bai also begins to laugh but continues to introduce new information saying "and", but then hesitates "er" (line 7). As she hesitates, laughing, Mike also begins to laugh (line 8). As Bai hesitates verbally, she shifts posture away from the table (straightening up) and partially retracts her gestures so that her forearms are now resting on the table and her fingers are no longer in contact with its surface (Fig. 5a). At the same time as this partial retraction occurs, Mike is laughing and says "okay haha wait haha wait haha let's see" (line 8). The third peer, Chen, is watching Mike during his utterance and also begins to laugh (line 9). 
6 LI [hahahahah

7 BAI [and er- [hahahahahahahahahahaha

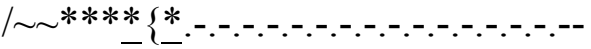

8 MIK [haha okay\# haha wait haha wait [lets see

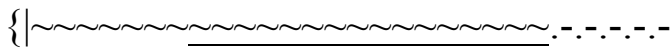

prehensile grip, both hands, movement towards diagram

$9 \mathrm{CHN}$

[hahahahahahaha

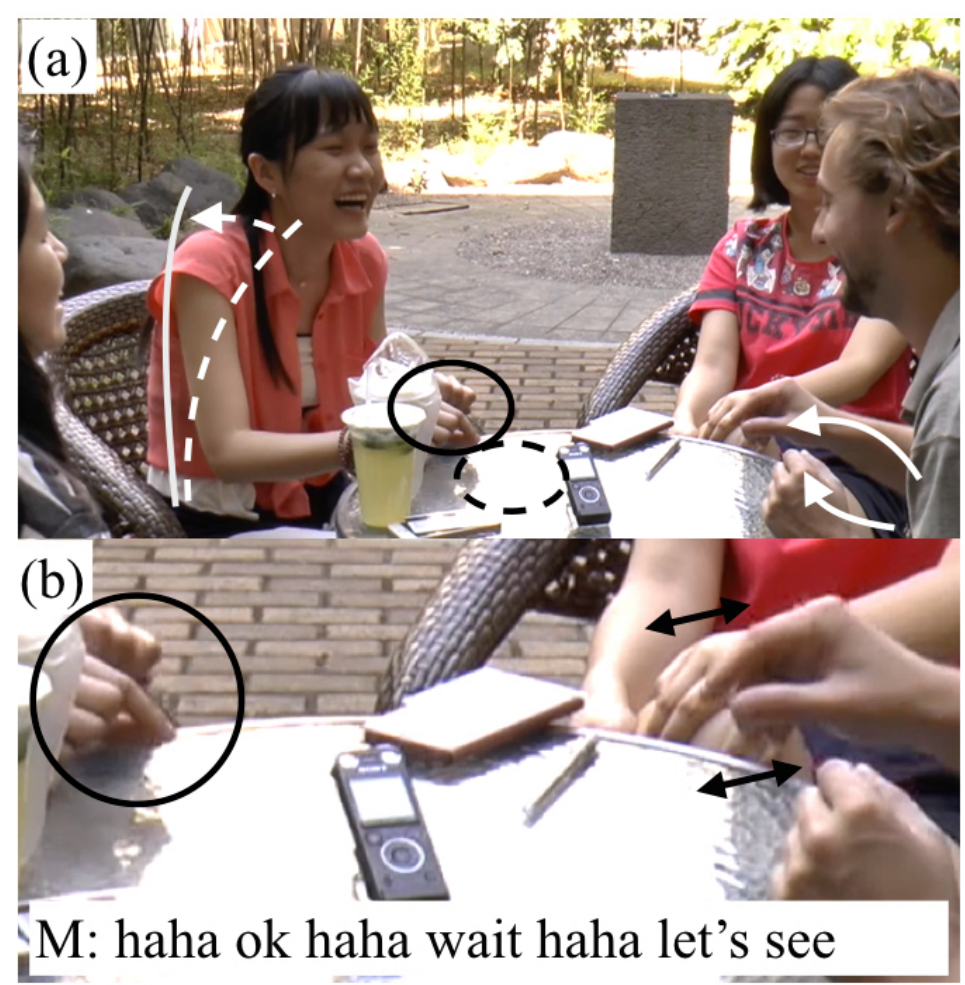

Fig. 5. (a) Bai partially retracts gesture and shifts posture away from the table; (b) Close up: Mike hesitates to 'grasp' the virtual diagram

At this point in the discourse, the group appear to have encountered an 'instance of communication breakdown' (Williams 1999). However, the nature and cause of this problem is not yet immediately clear from the discourse. Though Bai has selfcorrected a pronunciation mistake ("China"), she does not seem to be otherwise struggling with verbal expression (Ohta 2001). Furthermore, gestural depictions like this are common in face-to-face communication and situated activity (Streeck 2009; Müller 2014), as is the coupling of gestures to material objects in the surround (Goodwin 2007; Hazel 2014). Nevertheless, Bai has received no feedback from Mike on her initial answer. She has hesitated ("and er") and interrupted her diagramming. The group have engaged in an episode of shared laughter, which may be evidence of interactional trouble (Petitjean and González-Martínez 2015), such as awareness of 
inadequacies of expression (Potter and Hepburn 2010; Glen 2013). Different to these previous studies of laughter during interactional trouble in verbal language, however, any inadequacies in the current interaction appear to be with Bai's gestural expression. Furthermore, the intended beneficiary of her explanation, Mike, has now interrupted her with an explicit request to "wait" (i.e. to momentarily suspend a course of action; Keisanen, Rauniomaa and Haddington 2014). To help understand the origin of this breakdown, it is important to consider the gestures that Mike synchronizes with his request to Bai to "wait" (Fig. 5).

As Mike says "okay haha wait haha wait haha let's see", he raises his hands into the space in front of him in a prehensile posture - a configuration for grasping (Streeck 2009: 48). Following Streeck (2009: 47-51), the hands in prehensile postures are configured "according to the properties of object and task" (p. 47) - they reflect the size and shape of what they are about to grasp. The specific configuration of Mike's prehensile posture suggest that he intends to grasp a thin flat object, which is consistent with the virtual diagram that Bai has been elaborating on the table top. This configuration involves forefinger and thumbs extended and in close proximity (see Fig. 5b). However, rather than completing a reach or a grasp, Mike moves his hands in this configuration back and forth in the direction of the diagram space. He prepares a grasping gesture but hesitates to perform it. With this combination of gesture and speech, we propose that Mike is indicating that (a) he has not understood the diagram, and (b) he is keen to offer assistance. The shared laughter suggests a group realisation that Bai's diagramming strategy has not been effective. This interpretation is supported by the following interactive sequence, during which all three peers now make suggestions as to how the diagram could be improved for clarity.

\subsection{Collaborative dialogue and assisted performance}

Bai now attempts the explanation a second time. Our analysis of the next interactive sequence will show how she tries to draw the diagram in a number of different ways. We will also show how Bai receives input from all the peers, whose own gestures figure saliently when they suggest to Bai how she can improve the comprehensibility of her diagram.

Bai starts by 'relaunching' her gestures from their 'provisional home position' (Cibulka 2015). She repeats "this is the China" (line 10; see next segment of transcript below) and also repeats her gesture of using the index fingers of both hands to symmetrically trace semi-circles that constitute the outline of "China" (Fig. 6a). However, she is now speaking louder and slower (cf. $<\mathrm{f}>$ and $<\mathrm{len}>$ in the transcript), which potentially reflects her awareness of the need to increase the comprehensibility of her explanation. Figure 6 also shows that Mike has not fully retracted his gesture, although he has modified the hand configuration from a prehensile grip to a fist (Fig. 6b). Cibulka (2015) referred to the region where gestures are performed as the 'stage' and observed that "[c]loseness (of the hands or the body) to the stage is generally associated with some sort of involvement in the interaction" (p. 5). In maintaining his 
hand 'poised' like this in the gesture space, Mike indicates he is on standby to assist with the task.

10 BAI $\quad<<\mathrm{f}><$ len $>$ em this is the\# china $>$

$\{\sim \sim * * * * * * * * * * * * * *$

both index fingers symmetrically trace semi-circles

MIK

\{-.-.-.-.-.-.-.-.-.-.-.-.-.-1

holds partial retraction

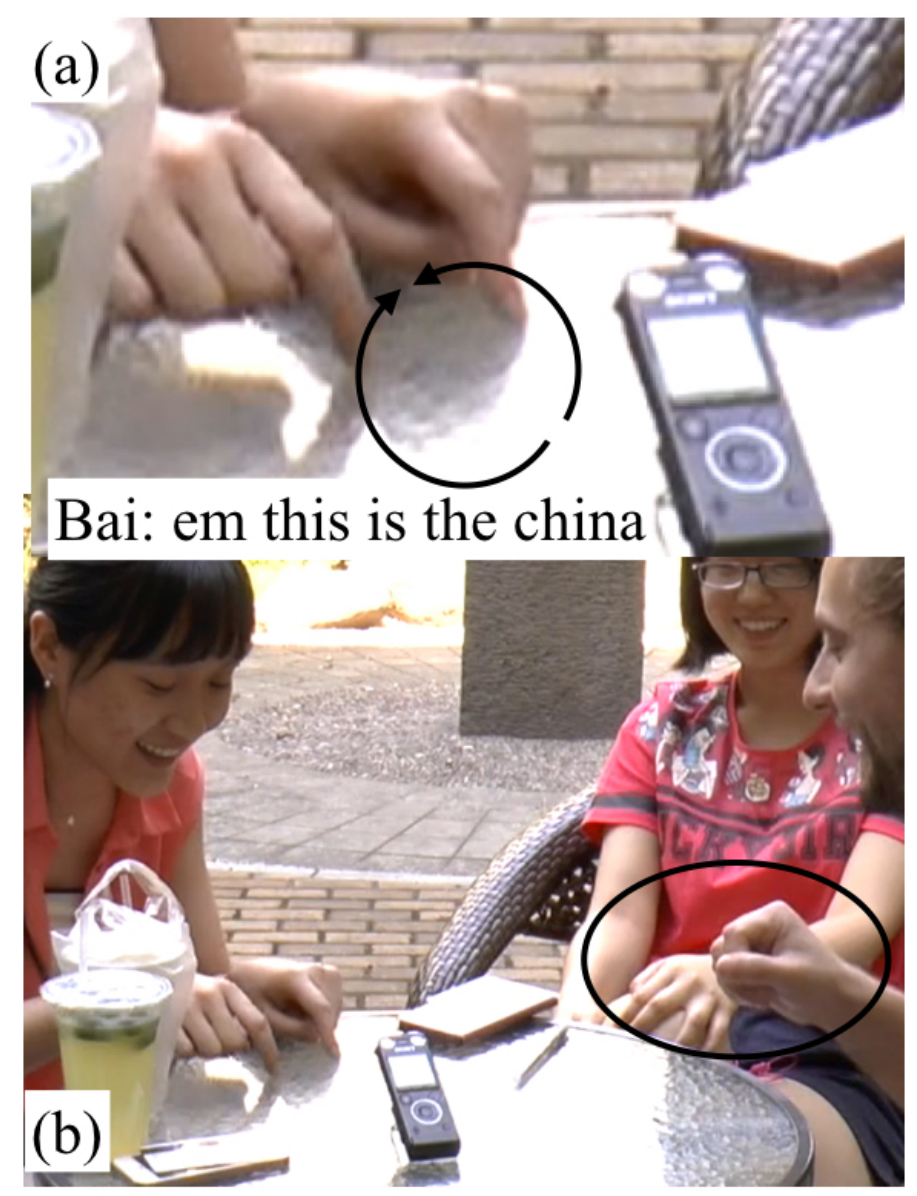

Fig. 6. (a) Bai begins second attempt, outlining symmetrical semi-circles for "China"; (b) Mike partially retracts his gesture

Bai begins to repeat her speech and gestures again, but starts her utterance this time with "em for example" (line 11). However, when she places her fingers in the same location to begin what would be a third drawing, the peer to her right, $\mathrm{Li}$, reaches into the space above Bai's gesturing hands while saying "maybe you should" (line 12). 
Without finishing this utterance verbally, Li performs a gesture that enacts the rotation of a two-dimensional disk-like object - her hands are open and flapped at the wrist so that the finger tips are directed downwards into the space above where Bai's hands are tracing the circle. She moves this configuration in a counter-clockwise motion as if to simulate rotating an object (Fig. 7a). With this 'embodied completion' - a hybrid move initiated by speech and completed with gesture (Olsher 2004; Mori and Hayashi 2006) - Li is suggesting to Bai that she could draw her diagram from a different, rotated perspective. Her speech and gesture can be understood as a multimodal prompt - the verbal component makes the polite suggestion ("maybe you should") while the gestural component shows exactly what is being suggested ("rotate the diagram'). When Li performs this multimodal prompt, Bai immediately interrupts her current speech and discontinues her drawing (line 11, Fig. 7b).

$11 \mathrm{BAI}$ [em for example this \#is- this is the $<<$ len $>$ china $>$ $\{/ \sim \sim \sim * * * * * * * * * * * * * * * / \sim * * * * * * * * * * * * * * * * * *$

both index fingers start to draw semi-circles / right index draws circle clockwise 12 LI [maybe you should $\{\mid \sim \sim \sim \sim \sim \sim \sim \sim \sim \sim \sim * * * * *-. . . . .-$.

hands enact rotation in space immediately above Bai's hands

13 MIK

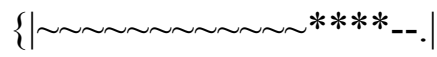

moves audio recorder from centre of table 


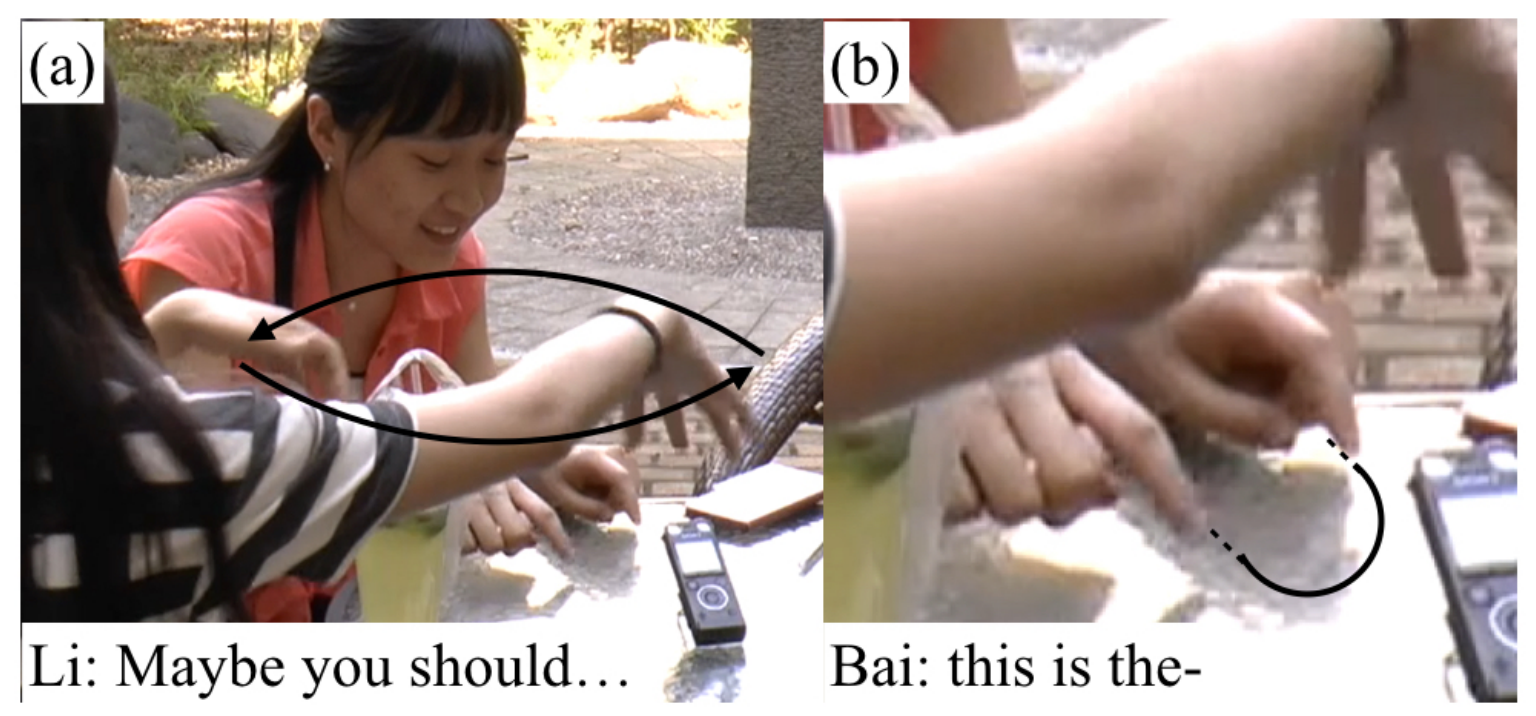

Fig. 7. (a) Li performs a 'rotation' gesture above Bai's hands (b) Bai discontinues her drawing of a circle

She restarts her utterance "this is the China", but instead of restarting the semi-circles that she previously drew, she now uses only the right index to draw the referent for "China" with a single circle in a clockwise motion (Fig. 8). As Bai is producing this modified gesture and repeating "this is the China", $\mathrm{Li}$ is retracting her gesture (also visible in Fig. 8). At this moment, Mike now reaches into the center of the table and moves the audio recorder out from the centre of the table to the edge of the table (Fig. 8). This opens up a larger space in which a diagram could potentially be drawn, both clearing his line of sight onto the diagram and preparing the table top coherently for the rotated diagram suggested by Li. 


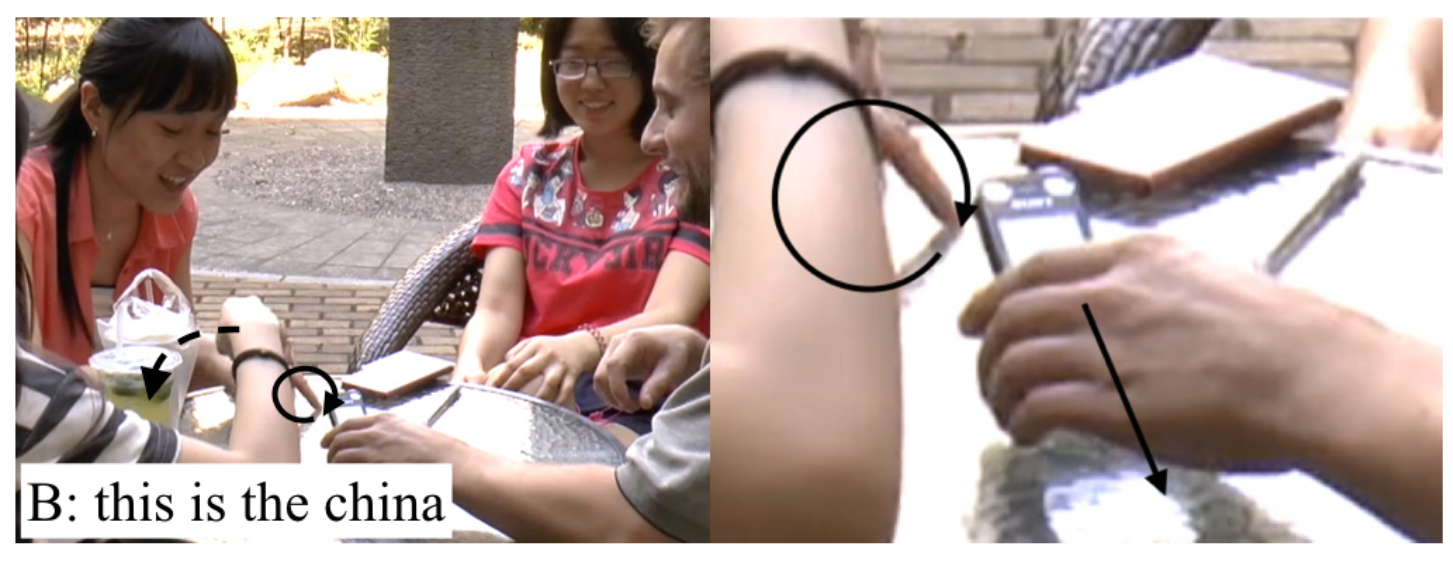

Fig. 8. Single index to trace "China”, Li retracting gesture, Mike moving recorder

As Mike finishes moving the audio recorder out from the centre of the table, Bai is completing a circle with her index finger whilst uttering "China" (line 11). However, as indicated by the code $<<l e n\rangle>$ in the transcript, she delays the completion of the word "China" by slowing down both speech and gesture (cf. $<<$ len $>$ ). This seems to be another indication that Bai is struggling, especially because, after uttering "China" slowly, she again bursts out laughing, partially retracts her gesture, and this time hangs her head as if overwhelmed by the difficulty of the task (line 13, Fig. 9). In research on laughter during job interviews, Glen (2013) showed that such post-hoc laughter may serve to mitigate the potential inadequacy of a response - people often "laugh in reference to their own talk that is hearably insufficient" (Glen 2013: 259). As for the peers, all hands are now "on deck": Li, Chen and Mike have their hands poised above or near the virtual object that Bai was producing, and at least two peers can be seen still looking at this space instead of looking at Bai. 


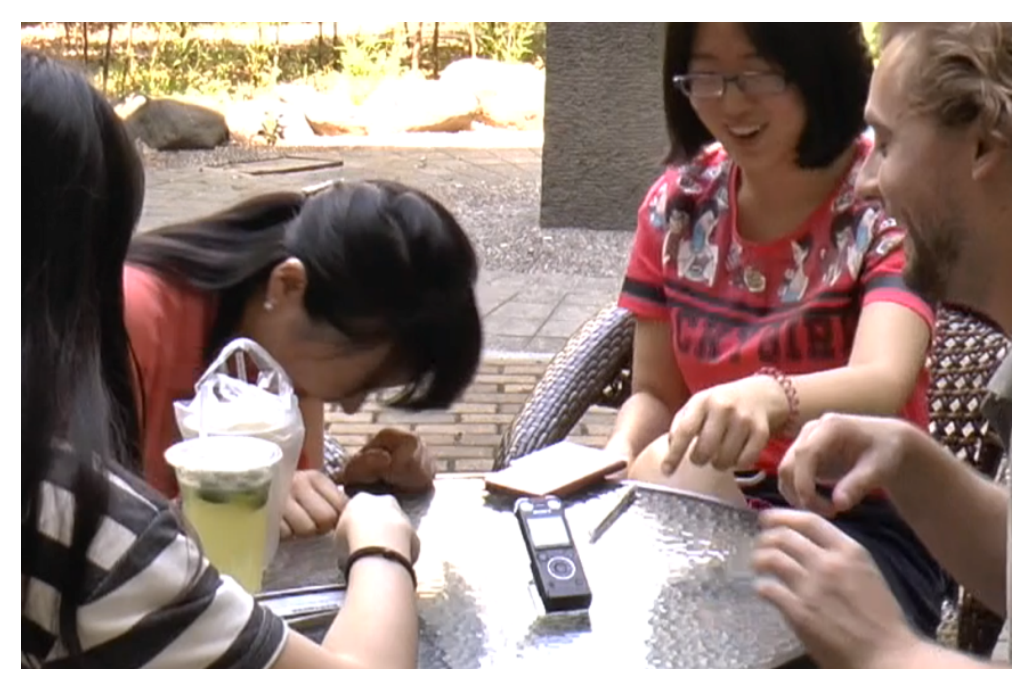

Fig. 9. Bai bursts out laughing, hangs head, and partially retracts her gestures; all peers have hands near the diagram space and two are looking at it

As Bai's head is hung, the peer to her left, Chen, now provides a form of assistance. Chen starts to point with an index finger to the space that Mike has just cleared, but her speech is inaudible during this segment. She first points with her left hand (Fig. 10a), then with her right (Fig. 10b).

13 BAI [hahaha

hangs head and partially retracts gestures

14 MIK [hahah[ah

$15 \mathrm{CHN} \quad$ [(inaud.)\#

$\mid \sim \sim \sim * * *\{* * * * * * * * / \sim \sim * * *\{* * * * * * * * .-. . .-$.

left index to space where audio recorder was, then right index

16 MIK [ok lets try to think how we can do this $\{\mid \sim \sim \sim \sim \sim \sim \sim \sim * * * * * * * * * * * * * * *$-.-.-.-.-.-.-.-.-.-.-.-.-..| raises hands and enacts rotating a disc-like object [erm

adjusts position, prepares gesture, hands make contact with $\mathrm{CHN}$ 's 


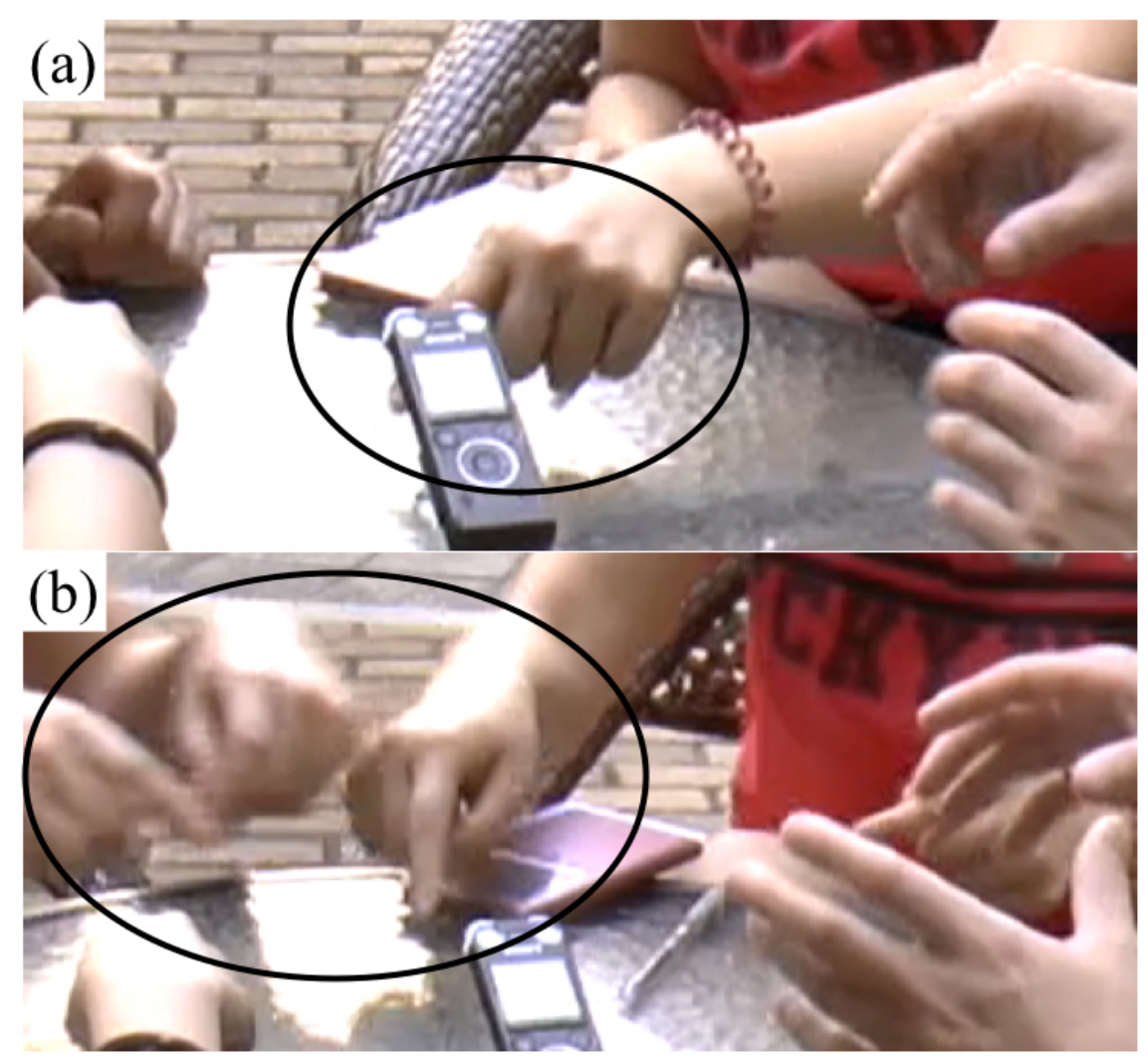

Fig. 10. (a) Chen points to space where audio recorder was, first with left, (b) then with right hand

As Chen points with her right hand, Bai adjusts her position so that she moves clockwise further around the table and prepares to gesture in the space that Chen is pointing in (Fig. 11a). As Bai's hands enter the space where Chen is pointing, Bai says "erm" (line 17) as her hands make contact with the right hand of Chen, who stops her pointing gesture and subsequently retracts her hand (Fig. 11b). This creates what could be called a 'gestural interruption', with which Bai indicates to Chen that she has understood the suggestion of drawing the diagram more centrally. During this interruption, Mike also provides a further form of assistance. He raises his hands in an open and curved shape as if to enact holding a disk-like object, then rotates them slightly while saying "OK let's try to think how we can do this" (line 16; Fig. 11b). The expression "do this" refers explicitly to the activity of drawing a map of China on the table, while "let's" and "we" suggest his willingness to collaborate and coconstruct. He could be using his gestures to model the activity for both himself and the speaker at this point. Though not evident in the screenshot, he is also adjusting his position by shifting clockwise to his right hand side, further aligning his perspective with the one that Bai is drawing her diagram from. As can be seen in this Figure, all students still have their hands either on the table or gesturing in the space above it. 


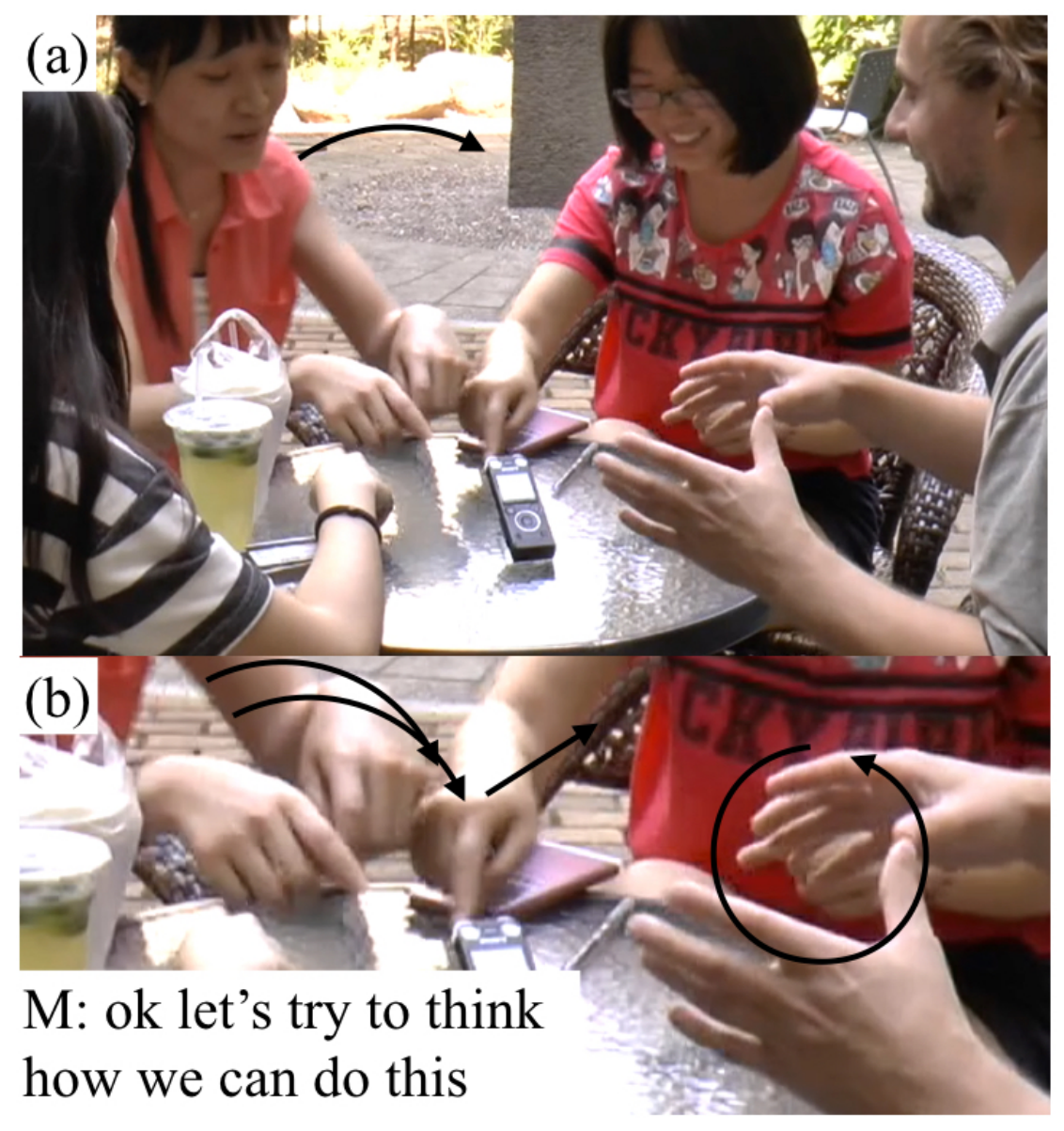

Fig. 11. (a) Chen points to space where audio recorder was with right hand, Bai produces a gesture in the same space, Mike enacts rotating a disk-like shape; (b) Close-up

To summarise the interactive sequence just analysed, as Bai has made further attempts to diagram local geography on the table-top, the group has deployed several forms of assistance in a coherent succession. Li used her gestures to suggest rotating the diagram, then Mike cleared a space in the center of the table. Chen specifically pointed to this new space, then Mike began to model a rotated diagram and invited the speaker to collaborate. The main message from these peers seems to be that Bai should draw the diagram from a rotated perspective, namely that of the intended beneficiary sat opposite to her. Laughter in the discourse is further evidence of the group's awareness of and orientation to inadequacy of expression or interactive trouble (Glen 2013; Petitjean and González-Martínez 2015; cf. Jefferson 1985). Bai's subsequent shift around the table towards where Mike is sitting - as far as is possible given they are separated by a peer - and her initiation of new gestures in that position supports the idea that she is attempting to integrate this feedback as she proceeds.

This shift in perspective is needed because Mike lacks common ground with the Chinese students about the relative location of Anhui (hence his question that motivated this collaboration). Any problems that Bai is experiencing in diagramming local geography are exacerbated by Mike's lack of epistemic access on the relevant 
domain of knowledge (Stivers, Mondada and Steensig 2011). Since Bai is diagramming local geography from her own perspective, Mike must interpret the virtual map 'upside down' or try to rotate it mentally. In Williams' (2011) study of gesture in collaborative scientific reasoning, the students naturally aligned their gestural depiction with the perspective of their addressees. This is a strategy that Bai did not adopt on her own, but has now begun to try, following assistance from her peers. In the interactive sequence that follows, Mike now participates more actively in the diagramming activity by co-constructing elements of the diagram with Bai.

\subsection{Co-construction}

Having adjusted her seating position, Bai is now further around the table towards the peer to her right: her neck, torso, arms, and wrists are also visibly contorted, and her head is cocked (Fig. 12a). From this new position, Bai begins a third attempt to use gesture to diagram the relative location of Zhejiang and Anhui province. There are several indications that she is making an additional effort to draw the diagram from a perspective that will be easier to understand for Mike, the intended beneficiary. First, her hands are now in a space that is more central on the table than they were before. Second, although she begins by repeating the same technique of using one finger to trace the outline of a circle as she again says "this is China" (line 18), she now draws the circle anti-clockwise (Fig. 12b). This reverse direction could be her attempt to take into account the perspective from which Mike would be viewing the gestures. 
$18 \mathrm{BAI}$ this is china [and this is] Zhejiang (.)

$* * * * * * * * * * / \sim \sim * * * * * * * * * * * * * *$

right index traces circle counter-clockwise

19 MIK

[ok \#this is china]

$\{\mid \sim \sim * * * * * /-.-.-.-.-* * * * * *$

right hand raised pointing to diagram, then mirrors Bai's point onto table

$20 \mathrm{BAI}$ and this is er::: \#shanghai and er \#this is fujian

// ******************/ **************

right index points on table / left index finger establishes relative location

$21 \mathrm{MIK}\{$ ***************************/ $* * *$ ***********

adjusts location of index finger to mirror the positioning of Bai's index finger

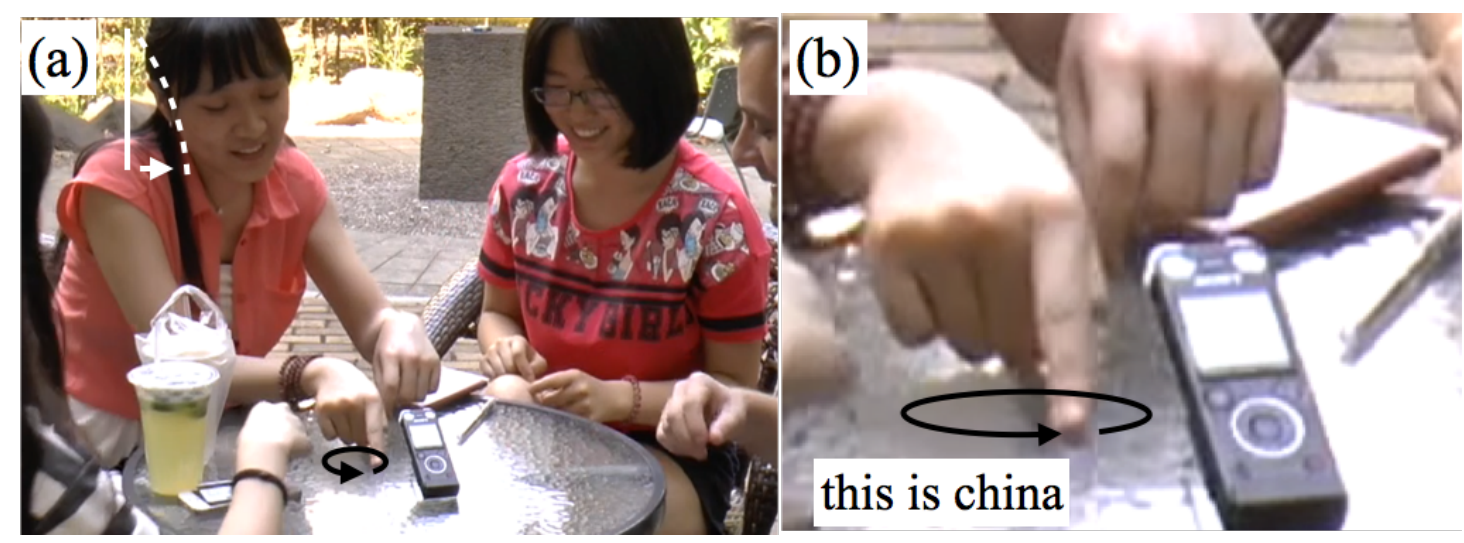

Fig. 12. (a) Bai begins third attempt in new position, outlining with one finger now anti-clockwise with head cocked to suggest new focus; (b) Close-up

It can now be seen how Mike now takes a much more collaborative role in the explanation and begins to co-construct the diagram with Bai. Specifically, he starts to use his own gestures to mirror Bai's gestures as she begins to elaborate on her drawing. As Bai moves and positions her hands on the table, Mike moves and positions his hands similarly. Having traced a circle to represent "China", Bai continues "and this is Zhejiang" (line 18), Mike overlaps and says "OK this is China" (line 19), visibly cocking his head too, as if in attempt to align with Bai's perspective. His index fingers are extended on both hands, and his right hand is beginning to point towards the new diagram that Bai is elaborating (Fig. 13). 


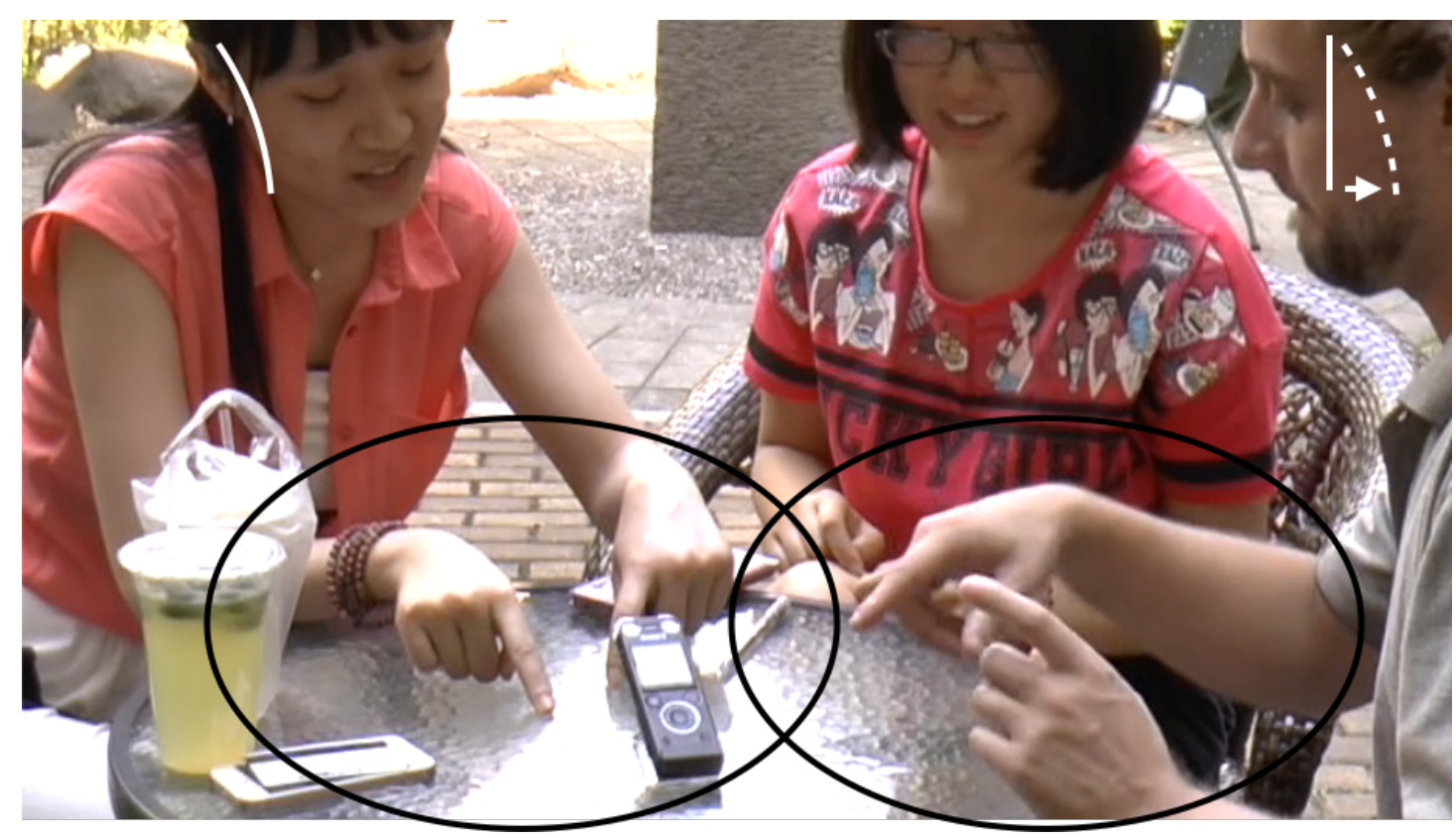

Fig. 13. Mike beginning to point to diagram that Bai is elaborating in a new space

As Bai continues "and this is Zhejiang and this is err Shanghai" (line 18-19), she starts using her index fingers to point to individual locations on the table again. She points once as she utters "this is Zhejiang" and once as she utters "Shanghai". When she did this in her earlier attempt, recall that she used her right hand first then her left hand (cf. line 4, Fig. 3). In this renewed attempt, she is now using her left hand first then her right hand. This could be further evidence that she is making efforts to shift to the perspective of her addressee. Mike now moves his right index finger specifically into the diagram space where Bai's hands are (Fig. 14a). As Bai now elaborates her diagram by pointing to a series of new spaces and uttering "Zhejiang" "Shanghai" and "Fujian" (lines 18-20), Mike uses his finger to follow Bai's finger as she creates each one of these new locations (Fig. 14b). In mirroring Bai's pointing gestures, Mike is using his own gestures to help keep track of the spatial locations that Bai is describing. This will also signal to Bai his engagement in and understanding of the task to Bai. This 'lead-follow' pattern has been observed elsewhere as characteristic of multimodal collaborative discourse, as by Arnold (2012) in his study of gestures during informal instruction at a bike repair workshop. 


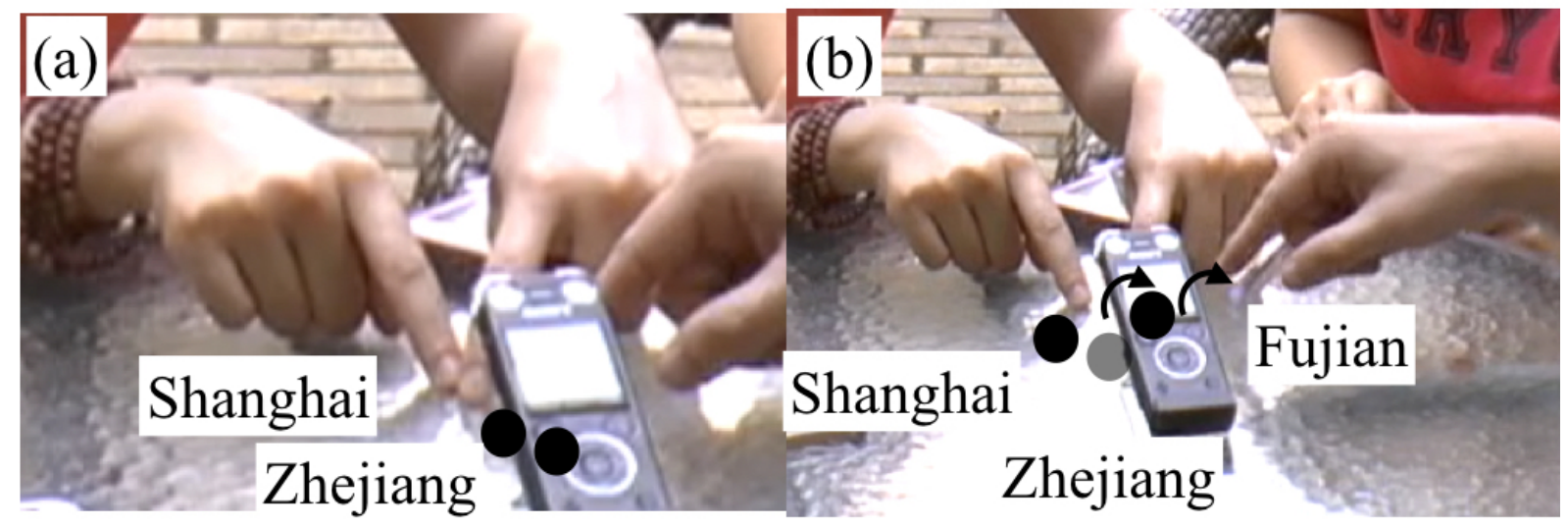

Fig. 14. (a) Mike using his own finger to follow each one of Bai's points that correspond to the locations being uttered ('Shanghai', 'Fujian'), (b) Close-up

Having illustrated the location of relevant cities and provinces, Bai now utters the key location whose whereabouts originally motivated her answer: "and this is Anhui" (line 21). However, as she is saying "and this is", the peer to Bai's left, Li, starts to laugh, and raises her hand to her face (line 22, Fig. 15). The reason for this laughter, we believe, is that in this attempt at the diagram, although Bai has adjusted to a position that is potentially easier to be understood from, she has increased the complexity of her explanation by including "Fujian", which is a province that she has not previously mentioned. From Bai's facial expression, it is clear that she is struggling to suppress her own laughter, which also leads to the prolongation of the word "is". This suppression could be a sign of 'troubles-resistance' - Bai is aware of Li's critique and "potentially moving towards laughter" (Jefferson 1985: 354), but she maintains composure and finishes her utterance (Fig. 15). 
$>$ MIK

$21 \mathrm{BAI}$ and er [this \#is:::] anhui [province] and er this

$\{/ \sim \sim \sim \sim * * * * * * * * * * * * * * * * * * * * * *$

right index finger points (with audible thud)

22 LI [haha]

23 MIK [anhui so \#n-]

$\{* * * * * * * * * * * * * * * * * * * * / \sim * * * / \sim \sim * * *$

mirrors point for 'anhui' / open palm lateral held vertical

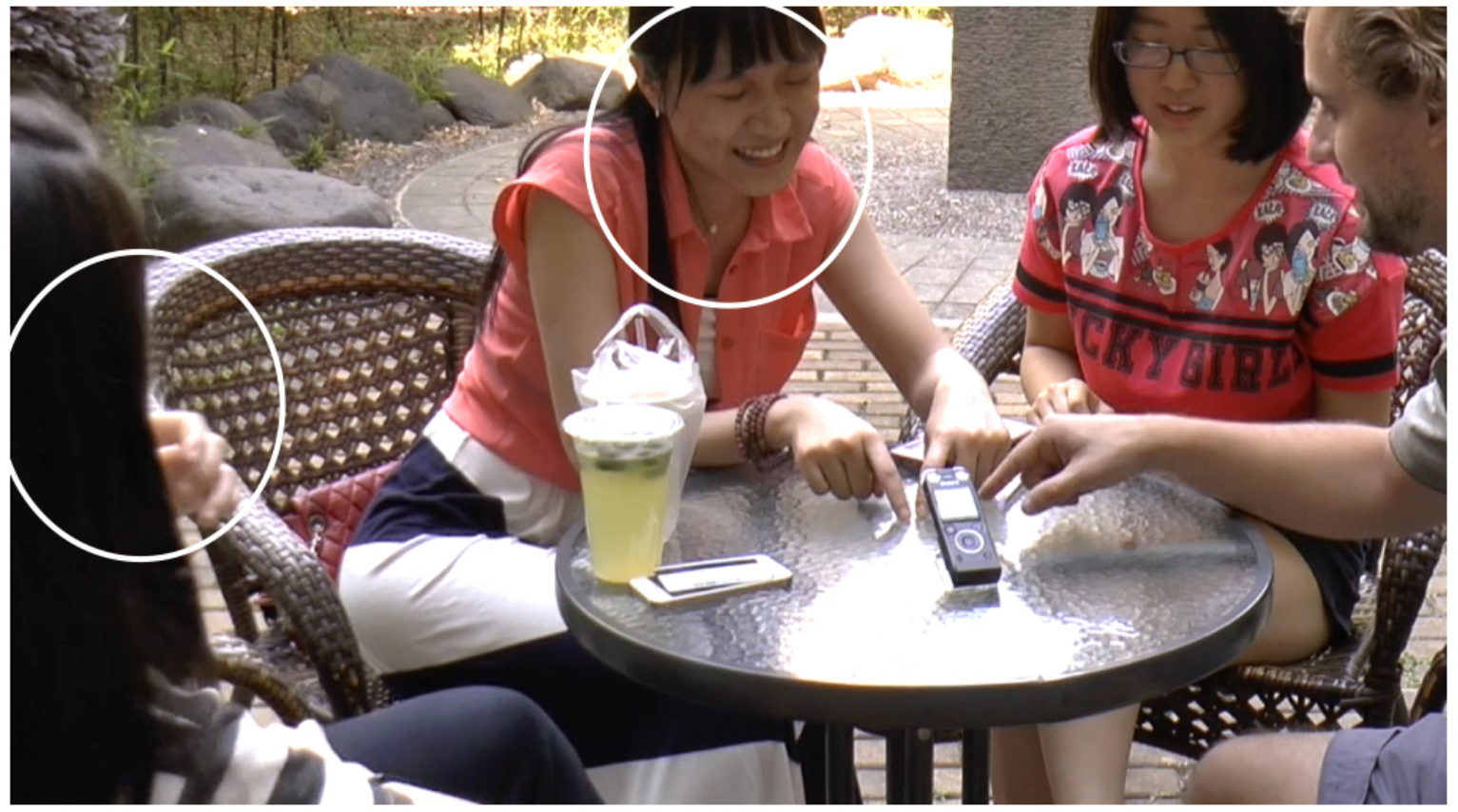

Fig. 15. Li laughs and raises her hand to her face; Bai maintains composure and finishes utterance

Bai's pointing gesture onto the table with "Anhui" creates an audible thud in the audio recording, and with this action, she shifts gaze to Mike. However, Mike is still focusing on Bai's gestures, to which he is also pointing (Fig. 16a). After saying "this is Anhui" and without establishing mutual gaze with Mike, Bai shifts gaze back to the diagram. Mike now withdraws his hand from the diagramming activity, shifts gaze to Bai, and says "anhui so n-" performing a gesture with a flat open hand held vertically in the sagittal axis - indicating absolute north (line 23, Fig. 16b). This gesture 
supports our interpretation that he was about to say "so north", which would constitute an answer to the question he originally asked and could be his attempt to resolve the collaborative activity. But when he sees that Bai is refocused on her diagram, he interrupts his speech, discontinues his gesture, and returns his hand to its previous activity of mirroring Bai's pointing to the different locations.

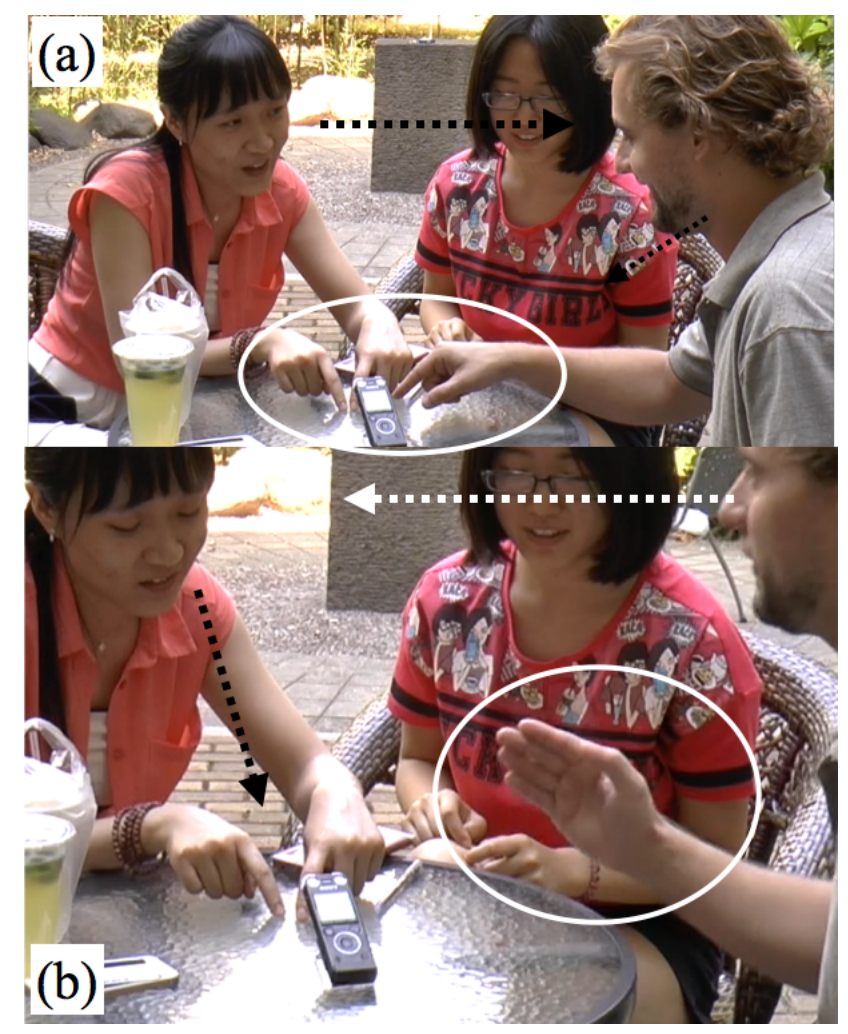

Fig. 16. (a) Bai shifts gaze to Mike, who is gazing and pointing at the diagram; (b) Mike seeks clarification on cardinal direction with a gesture but Bai has returned gaze to her diagram activity

Despite having established the location of Anhui, Bai begins a final repeat of the various locations of the diagram she has just drawn, again coordinating pointing gestures with spaces on the table whilst uttering the names of cities and provinces. However, she begins with a hesitative utterance that has a number of repeats and restarts, saying "and er this is er this is shan- this is shanghai" (line 24). As she is hesitating in speech, she is also hesitating in gesture, because instead of a definite point onto the table, the index fingers of both her hands are moving up and down but not contacting the table. This multimodal hesitation, verbal and gestural, could reflect the difficulty of drawing the map from the new, rotated perspective, and the hesitations could reflect her mental processing of this. In other words, she is experiencing a cognitive dissonance and this is reflected in her motor coordination. Additionally, she could be perturbed by the request for clarification from Mike, which she ignored. After this initial hesitative start to her final drawing episode, Bai 
continues to add "Zhejiang" and "Suzhou" to her map (line 26). However, she adopts a different form of gesturing to do this. Rather than using the fingers of separate hands to consecutively point to locations, she keeps the finger of her left hand fixed on the table, then uses each finger of her right hand to indicate a different location. The result is that at the end of this utterance, she has three fingers now placed on the table for the locations she has mentioned (Fig. 17a and b).

$24 \mathrm{BAI}$ and er this is er this is shan- this is shanghai

$\{/ \sim \sim * * \sim * * \sim \sim * * * \sim \sim * * * * * * * * * * * * * * * * * * *$

both index fingers moving up and down, hesitating

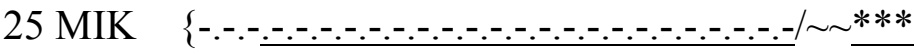

partially retracts, holds, then returns right index to focal space

$26 \mathrm{BAI}$ this is er zhejiang and this is \#err suzhou

$\{* * * * * * * * * * * * * * * * * * * * / \sim * * * * * * * * * * *$

uses right index for 'zhejiang'/ right middle finger for 'suzhou'

$27 \mathrm{MIK}\{$ ***********************************

right index held in the diagram space

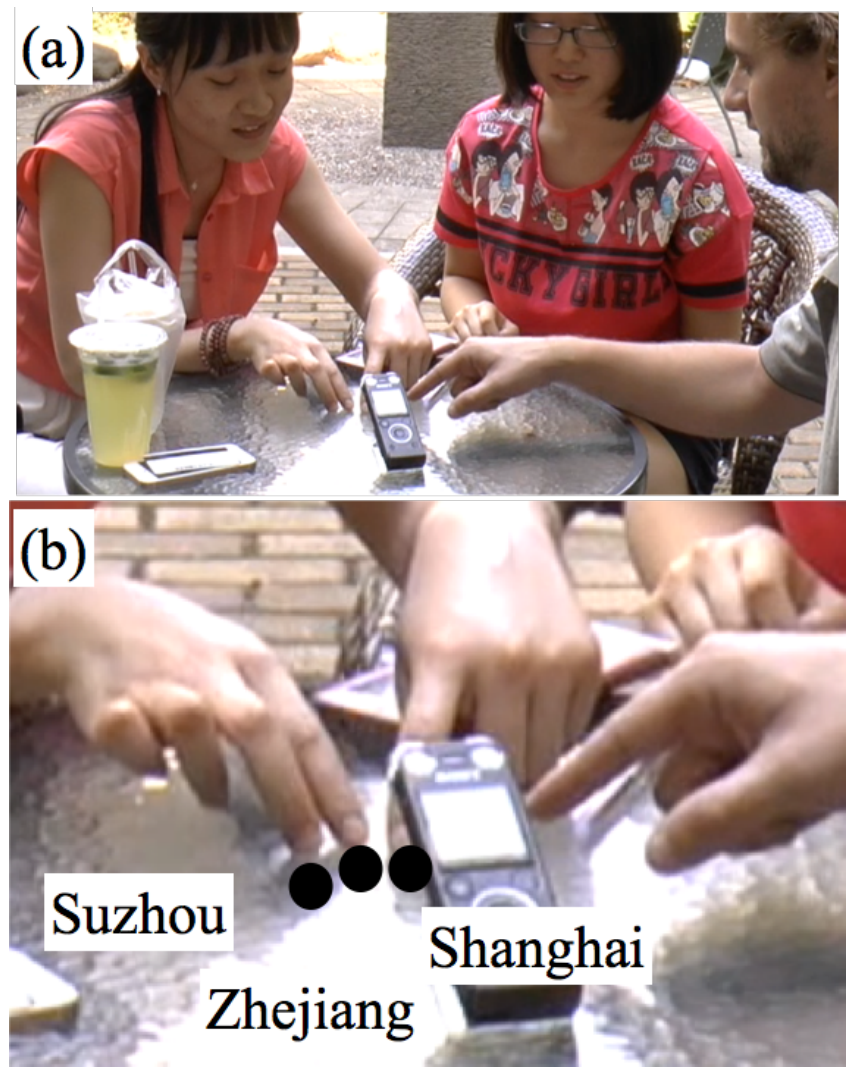

Fig. 17. (a) Three fingers being used as place holders, (b) close up 
As she now begins her utterance with which she is going to indicate Anhui (line 28), she says "and er this is" while using all three fingers on her right hand as placeholders for the different cities. She now brings a fourth one in (having to release the others) in order to coordinate a point with "Anhui", which she says whilst laughing (hence "an ha-hui-ha-hui-ha"). Her gesture with the fourth finger now looks awkward, like a beginner playing the piano on the table (Fig. 18a). Chen and Li burst out laughing (lines 30 and 31). Chen reaches over and pats Bai on the shoulder (Fig. 18b), as if either to acknowledge the difficulty of the task, congratulate Bai for completing it, or maybe even as a sign that she should stop. Note also in the figure how Mike has continued his activity of using his own gestures to mirror each of Bai's points until the end of the description (lines 25, 27, and 29). 
28 BAI [and er this is\#] [an -ha-hui-ha-hui-ha]

$\{* * * * * * * * * * * * * * * * * * * * * * * * * * * . .-$.

uses right ring finger for 'anhui'

$29 \mathrm{MIK}\{* * * * * * * * * * * * * * * * * * * * * * * * * * * * * * * * *$

right index held in the diagram space

30 LI [hahahhahhahhahhah]

$31 \mathrm{CHN}$ [hahahah]

Chen, laughing, places a hand on Bai's shoulder

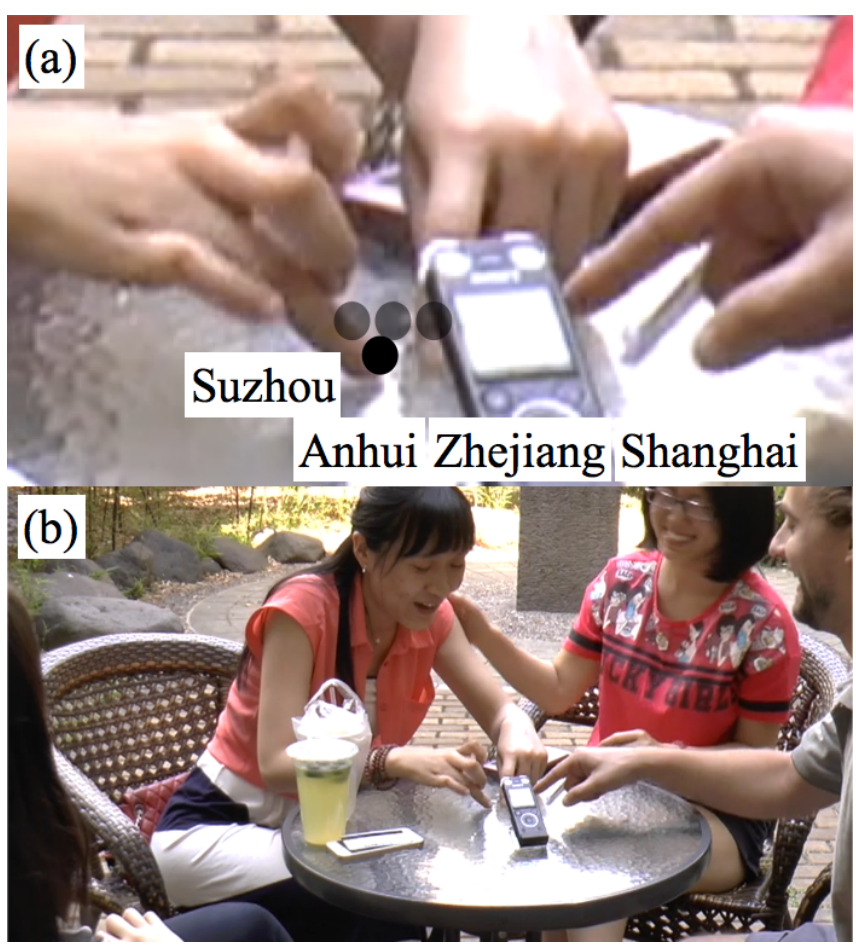

Fig. 18. (a) Fourth finger used to complete the diagram with "Anhui"; (b) Chen pats Bai on the shoulder, Mike is still mirroring Bai's gestures

This marks the end of Bai's explanation and diagramming activity because her hands now completely retract from the table and Mike begins to formulate his own understanding, as described below.

\subsection{Reaching agreement and resolution of the task}

When Bai retracts her gestures from the table, Mike produces a series of utterances to express his own understanding of the location of Anhui in relation to Zhejiang. In this display of new knowledge (Stivers, Steensig and Mondada 2011), he adopts a different way of gesturing altogether. 
Mike begins with the discourse markers "OK SO" (capitals indicate stress), which clearly announce his aim of concluding the activity. As he then says "it's south of south the... south of Suzhou" (line 32), he gestures not on or towards the table, but in the space immediately in front of him (a region traditionally referred to as "gesture space"; McNeill 2005). In this space, he prepares a gesture in which the hands are flat with the palms oriented down, the left palm positioned above the right. With this gesture, he is representing the relevant region of China in the vertical plane. Because he moves the bottom palm repeatedly downwards as he looks at Bai and says "so it's south of Suzhou", the top hand is being used to represent the location of Suzhou and the downward movement refers to the territory south of there (i.e. 'below') (Fig. 19a). Bai overlaps "yeh, yeh, yeh" (line 33), but the peer to his right, Chen, overlaps "East" (line 34; note that 'East' would again be incorrect). Mike now says "but so north" (line 35), switching perspectives to consider the position of Anhui in relation to the group's current location and thus returning to his original question about the province's location. He achieves this shift in perspective gesturally too, because he reconfigures his gesture so that the forearms are no longer one above the other with the palms facing down, but instead are vertical so that the palms are facing each other laterally and the fingers are pointing upwards i.e. north if a map were being shown in this vertical plane (Fig. 19b). However, in response to Chen's "East" he shifts gaze to her and interjects "no West" (line 35) and simultaneously flaps his right hand to intersect with his left, which in the logic of his diagram indicates 'north west', because his left hand maintains the orientation used to indicate north while the right hand connects that laterally to mean west (Fig. 19c). As he does this, Chen selfcorrects "uh west" (line 36), then after his utterance repeatedly affirms "west west" (line 36), while in the meantime Bai also confirms "west" (line 37). Still maintaining a gesture hold, Mike now shifts gaze back to Bai and repeats "north west" with a nod of the head that solicits a confirmation (line 38, Fig. 19d). When Bai and Chen then overlap with "yeh" (lines 39-40), Mike says "o::h ok" (line 41), extending the vowel of "oh" with falling intonation, tossing his head back and retracting his gestures (Fig. $19 \mathrm{e})$. 
32 MIK OK SO it's south of south [the (.) [south\# of Suzhou / **********/****************************

flat hands raised, palms facing down, left above right, right palm moves downward with 'south'

33 BAI [yeh yeh yeh]

$34 \mathrm{CHN} \quad$ [E::ast

35 MIK (.) but [so \#north] no west\# [you mean]

/ ************/****************

orients right palm 'north' / orients right palm 'West'

$36 \mathrm{CHN}$ [uh west] [west west yeh]

37 BAI west

$$
\text { ------>BAI }
$$

38 MIK north \#west (nods head)

$* * * * * * * *$

39 BAI [yeh yeh]

$40 \mathrm{CHN}$ [yeh]

$41 \mathrm{MIK} \quad \mathrm{O}: \mathrm{h}$ \# $\mathrm{ok}$

$-\cdot-\cdot-\cdot-\cdot \mid$

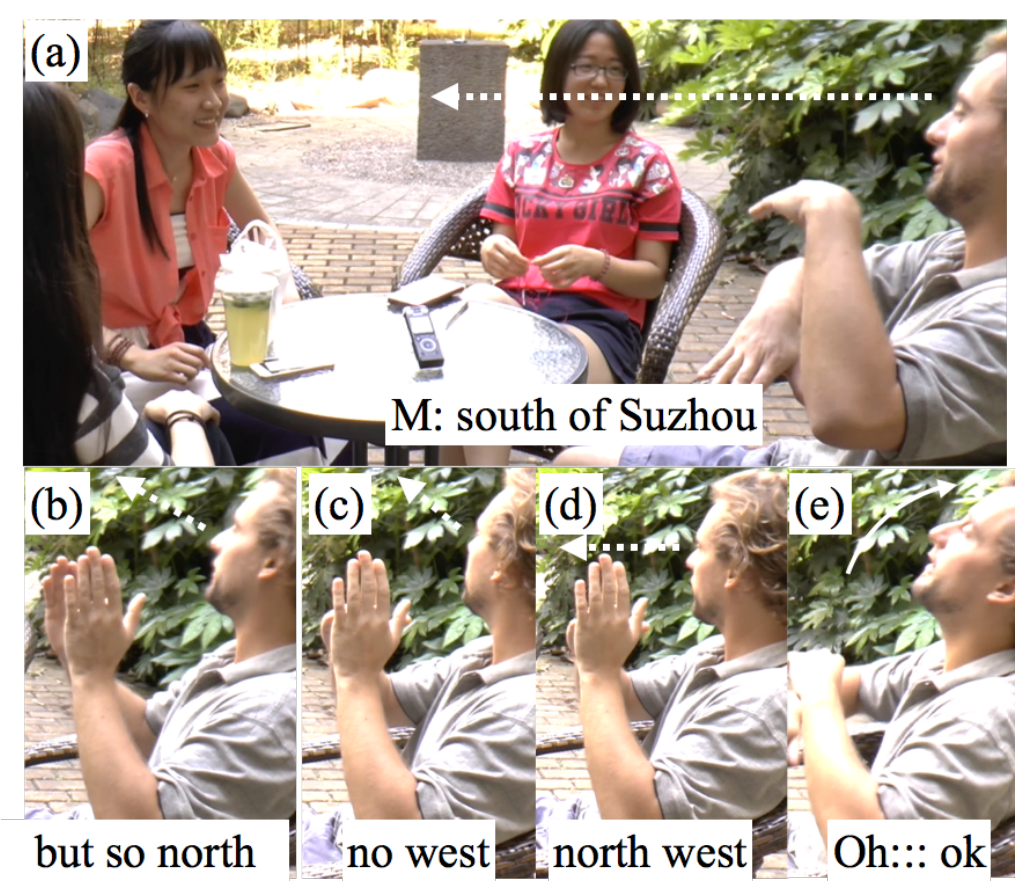

Fig. 19. Mike uses a different gestural strategy in showing his own understanding

The episode of collaboration can be seen as ending now. Not only has Mike shown that he has understood ("Oh ok") a 'change-of-state' token that marks the shift from 
"not knowing to knowing” (Stivers, Mondada \& Steensig 2011: 12), but after a short pause, Bai turns to Li and laughs, covering her mouth with an open hand while critiquing her own answer as "so complicated" (line 42; Fig. 20a). Mike rejects this critique "no no" and reassures Bai "that's ok", performing an Open Hand Prone gesture often observed with negative speech acts (Harrison in press), then immediately shifting topic to talk about "the taxi drivers" he has met from Anhui (line 43).

42 BAI hahaha so complicated

43 MIK no no that's ok it's ok (.)

4 because yeh I made and many of the taxi drivers are from there

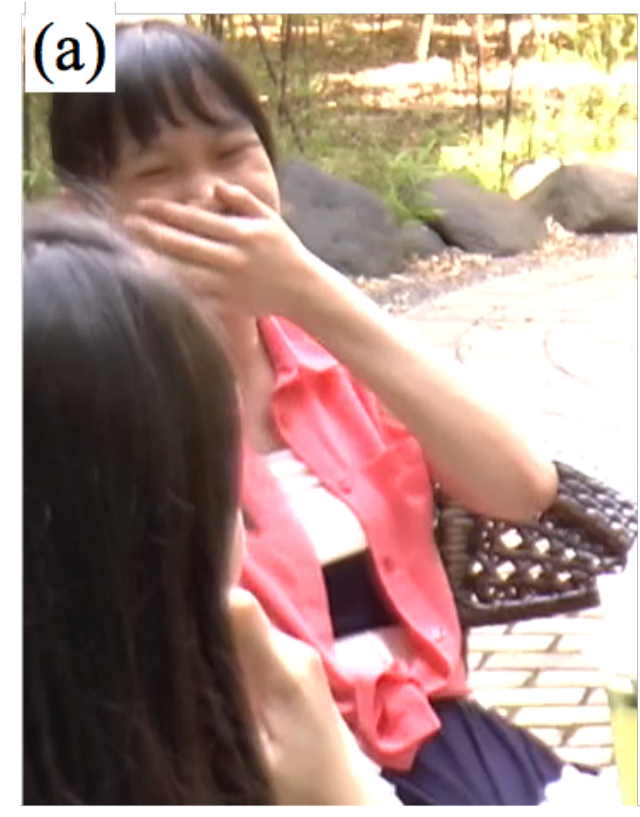

\section{B: hahaha so complicated}

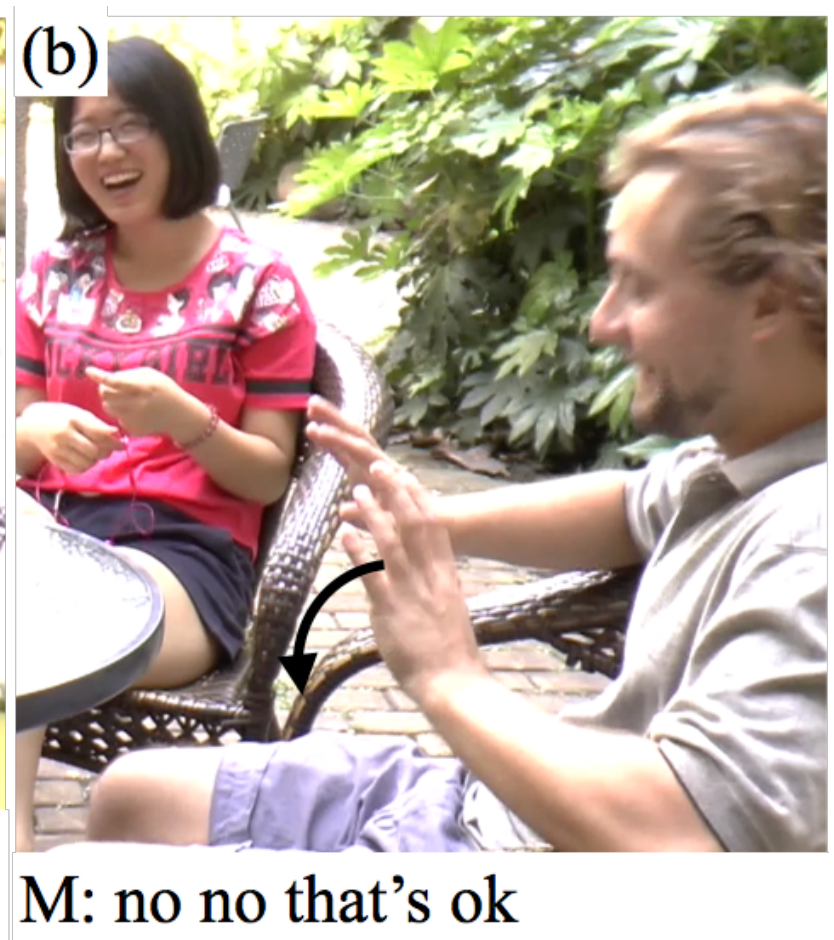

With this mention of "taxi drivers", the group segues into a different topic. There is no further mention of the location of Anhui after this point.

\section{Discussion}

The aim of this paper was to demonstrate that the genesis of collaborative dialogue among peers in group discussion may be focused on negotiating the form and organization of a speaker's gestures. In the interactive sequence we have analysed, communication breakdown occurred primarily because of the way a speaker was gesturing, and the assistance that peers then provided was accordingly designed to 
enhance the speaker's gestural performance. Though the role of gesture during L2 collaborative dialogue is well-understood (McCafferty 2002; Smotrova and Lantolf 2013; Smotrova 2014), gesture as the source of communication breakdown that triggers subsequent collaboration has previously not received equal attention. Our illustration of students critically focusing on gesture form during group discussion justifies the proposal to adapt the well-researched concept of Language Related Episodes (cf. Swain and Lapkin 1998) in order to include what we call 'Gesture Related Episodes'. By illustrating such an episode, our study has shed light on the problems that people can experience with gestures, what constitutes struggling in the gestural modality, and how people help each other to gesture more effectively in interaction. These features of the Gesture Related Episode will now be considered in relation to conceptual and conventional aspects of gestures, then discussed in relation to L2 concerns and knowledge asymmetries shaping the interaction.

Conceptually, the Gesture Related Episode that we have studied - a student using gestures to diagram local geography on a table-top - constitutes what Hutchins (2005) calls a 'materially anchored conceptual blend'. An aspect of the material surround is spontaneously drawn on as a concrete support to 'ground' an abstract conceptual model, which in our data was the student's map of the relative locations of Chinese provinces and cities. These kinds of blends are not only spontaneous, but also conventional. Streeck (2009) has argued, for example, that "[d]epiction is always a matter of convention" (p. 120), citing that "movements with an extended index finger are often meant to be seen as lines" (Streeck 2009: 121). Those lines must also be accessible to the intended beneficiary i.e. they must exhibit 'recipient design' (Streeck 2009). Previous studies of collaborative reasoning have shown how speakers take their addressee's viewpoint into account during gestural depictions (e.g. Williams 2011), but a lack of conformity to this expectation led the participants in our data to a communication breakdown.

When peers then began to assist the speaker's performance and deployed their own gestures specifically in relation to her gestures, they engaged in what Fricke (2014) has referred to as "deixis at signs", which occur "when the deictic object (demonstratum) is an entity that is interpreted as standing for something else" (p. 1816). In other words, though the peers did not go as far as to manipulate the speaker's hands or begin a gestural drawing themselves, which could have constituted an explicit gesture 'correction', they gestured above and onto the table as if the map being elaborated was a real artefact. As with the 'deixis at signs', the material structure being gestured on was being "interpreted as a sign for the intended reference object" (Fricke 2014: 1816) - the space was already 'standing in' for a map of China (hence semiotically and conceptually different to McNeill's "abstract diexis", which has been shown to create and track discourse referents during narrative; McNeill et al 1993). In our study, the use of gesture for "deixis at signs" - in this case gestures towards gestures, or 'meta-gesturing' - emerges as a particularly salient form of assisted performance during a Gesture Related Episode.

The success of gestural depiction in our data was jeopardised by two salient factors, namely the additional difficulty of communicating in an L2 (Ohta 2001) and 
the knowledge asymmetry between participants of the interaction (Stivers, Mondada and Steensig 2011). As Ohta (2001) observed, "when learners construct utterances in the peer setting, they must use working memory not only to formulate the utterance, but also to serve any phonetic, phonological, lexical, morphological, or syntactic problems that emerge" (p. 77). The Chinese students in the collaboration we filmed were highly proficient in English, but the task of describing local geography in an L2 may have influenced one speaker to neglect the recipient design of her gestures. Her trouble-related laughter (cf. Petitjean and González-Martínez 2015), self critique as 'too complex', and the abundance of assistance from peers further suggests this speaker was burdened by the task of L 2 production.

Any problems with gestures, however, were exacerbated by the American student's understanding of Chinese geography. The data offers an example of "how knowledge is managed in and through social interaction" (Stivers, Mondada and Steensig 2011: 7). Goodwin (1979) showed how people design utterances based on what they think their addressees know. In terms of this "epistemic access congruence" (Stivers, Mondada and Steensig 2011: 10), the lack of recipient design in the Chinese student's initial gestural diagram could relate to a "presupposition of epistemic access" that subsequently failed (p. 11). This 'epistemic asymmetry' revealed by Mike's inability (or unwillingness) to interpret an inverted map of China (or to rotate it mentally), then needed negotiation through additional language and gesture.

Breakdown and collaborative repair of gestures, therefore, was not only aimed at improving the design of the Chinese student's gestures, but also aimed at facilitating the American student's access to absent knowledge. Among various other intersubjective positionings in the data (such as gender and level of studies), this knowledge asymmetry relating to cultural background was particularly salient in influencing how the speakers produced and perceived gestures.

Unlike research on Language Related Episodes, this study of a Gesture Related Episode has highlighted the importance of gesture to collaborative discourse, defined as "the dialogue in which speakers are engaged in problem-solving and knowledge building" (Swain 2000: 102). Uptake of assistance during a Gesture Related Episode in our data contributed to the task of drawing a gestural map to represent relative locations of nearby cities, which in turn helped build a student's knowledge of local geography. The future study of GREs may help broaden our understanding of the different forms of gestural competence that people bring to group discussions, as well as the role of gesture in the assistance we provide each other when we interact.

Given the limitation of a single case analysis, a next step in this research may be to micro-analyse a collection of similar examples with the goal of developing a typology of the problems that people may experience with gesture and the forms of assistance those problems elicit from peers (cf. Stutzman 2017).

\section{ACKNOWLEDGEMENTS}

The authors wish to thank the participants of the study as well as Tetyana Smotrova, Robert F. Williams, and Daryl Johnson for comments on previous manuscripts. This 
work was supported by the Institute of Asia and Pacific Studies at the University of Nottingham Ningbo China.

\section{REFERENCES}

Alcón Soler, E. 2002. Relationship between teacher-led versus learners' interaction and the development of pragmatics in the EFL classroom. International Journal of Education Research 37: 359-377.

Arnold, L. 2012. Dialogic embodied action: Using gesture to organize sequence and participation in instructional interaction. Research on Language \& Social Interaction, 45, 269-296. doi:10.1080/08351813.2012.699256

Bressem, J. 2013. A linguistic perspective on the notation of form features in gestures. In C. Müller, A. Cienki, E. Fricke, S. Ladewig, D. McNeill \& S. Teßendorf (Eds.), Body - Language - Communication (Vol. HSK 38.1, pp. 1079-1098): de Gruyter.

Cibulka, P. 2015. When the hands do not go home: A micro-study of the role of gesture phases in sequence suspension and closure. Discourse Studies 17(1) 3-24.

Cienki, A., Bietti, L. and K. Kok. 2014. Multimodal alignment during collaborative remembering. Memory Studies 7: 354-369.

Debras, C., Horgues, C. \& S. Scheuer. 2015. The multimodality of corrective feedback in tandem interactions. Procedia - Social and Behavioral Sciences 212: 1622.

Edstrom, A. 2015. Triads in the L2 classroom: Interaction patterns and engagement during a collaborative task. System 52: 26-37.

Fricke, E. 2014. Deixis, gesture, and embodiment from a linguistic point of view. In: C. Müller, A. Cienki, E. Fricke, S. H. Ladewig, D. McNeill \& S. Teßendorf (eds.), Body-Language-Communication: An International Handbook on Multimodality in Human Interaction. (Handbooks of Linguistics and Communication Science 38.2.). Berlin, Boston: De Gruyter: Mouton, 1803-1823.

Glen, P. 2013. Interviewees volunteered laughter in employment interviews: A case of "nervous" laughter? In Glen, P. and E. Holt (Eds.) Studies of Laughter in Interaction (pp.255-276). Bloomsbury. 
Goodwin, C. 2007. Environmentally coupled gestures. In Duncan, S., Cassell, J. and E. Levy. (eds.): Gesture and the Dynamic Dimensions of Language (pp.195-212). Amsterdam/Philadelphia: John Benjamins.

Goodwin, C. 1979. The interactive construction of a sentence in natural conversation. In G. Psathas (Ed.) Everyday language: Studies in Ethnomethodlogy (pp.97-121). New York: Irvington Publishers.

Gullberg, M. 2013. So you think gestures are compensatory? Reflections based on child and adult learner data. In Flyman Mattson, A. \& Norrby, C. (Eds.) Language acquisition and use in multilingual contexts. Theory and practice (pp.39-49). Centre for Languages and Literature, Lund University.

Harrison, S. in press. The Impulse to Gesture. Where Language, Minds, and Bodies Intersect. Cambridge University Press.

Hazel, S. 2014. Cultivating objects in interaction: Visual motifs as meaning making practices. In Maurice N., Haddington, P., Heinemann, T. and M. Rauniomaa (eds.): Interacting with Objects: Language, materiality, and social activity (pp.169-194). Amsterdam/Philadelphia: John Benjamins.

Hutchins, E. 2005. Material anchors for conceptual blends. Journal of Pragmatics, 37, 1555-1577.

Hutchins, E., \& Nomura, S. (2011). Collaborative construction of multimodal utterances. In J. Streeck, C. Goodwin, \& C. LeBaron (Eds.), Embodied interaction: Language and body in the material world (pp. 289-304). Cambridge, England: Cambridge University Press.

Jefferson, G. 1985. On the organization of laughter in talk about troubles. In Atkinson, M. (Ed.) Structures of Social Action (pp.346-369). Cambridge University Press.

Jefferson, G. 2004. Glossary of transcription symbols with an introduction. In Lerner, G. H. (Ed.), Conversation Analysis: Studies from the First Generation. John Benjamins, Philadelphia, pp. 13-31.

Keisanen, T., Rauniomaa, M. \& P. Haddington. 2014. Suspending action. From simultaneous to consecutive ordering of multiple courses of action. In Haddington, P., Keisanen, T., Mondada, L. \& M. Nevile (Eds.), Multiactivity in Social Interaction: Beyond multitasking (pp. 109-133). Amsterdam; Philadelphia: John Benjamins Publishing Company. 
Kendon, A. 2004. Gesture: Visible Bodily Action as Utterance. Cambridge University Press.

Lantolf, J. 2010. Minding your hands: the function of gesture in L2 learning. In Batstone, R. (Ed.) Sociocognitive perspectives on language use and language learning (131-147), Oxford University Press.

Leeser, M. J. 2004. Learner proficiency and focus on form during collaborative dialogue. Language Teaching Research, 8(1), 55-81.

Matsumoto, Y. and Mueller Dobs, A. 2017. Pedagogical Gestures as Interactional Resources for Teaching and Learning Tense and Aspect in the ESL Grammar Classroom. Language Learning, 67 (1), pp.7-42. DOI: 10.1111/lang.12181

McCafferty, S. G. 2002. Gestures and creating zones of proximal development for second language learning. Modern Language Journal, 86 (2), pp.192-203.

McCafferty, S. G. 2006. Gesture and the materialization of second language prosody. International Review of Applied Linguistics in Language Teaching, 44(2), 197-209.

McNeill, D. 1992. Hand and Mind. What gestures reveal about thought. Chicago: University of Chicago Press.

McNeill, D. 2005. Gesture and Thought. Chicago: University of Chicago Press.

McNeill, D., Cassell, J., Levy, E. T. 1993. Abstract deixis. Semiotica, 95 (1/2): 5-19.

Mondada, L. 2011a. The management of knowledge discrepancies and of epistemic changes in institutional interactions. In Stivers, T., Mondada, L., and Steensig, J. (eds.). The Morality of Knowledge in Conversation (pp.27-57). Cambridge: Cambridge University Press.

Mondada, L. 2011b. The interactional production of multiple spatialities within a participatory democracy meeting. Social Semiotics 21(2): 283-308.

Mori, J. and M. Hayashi. 2006. The achievement of intersubjectivity through embodied completions: A study of interactions between first and second language speakers. Applied Linguistics 27/2: 195-219.

Müller, C. 2014. Gestural modes of representation as techniques of depiction. In C. Müller, A. Cienki, E. Fricke, S. Ladewig, D. McNeill \& J. Bressem (Eds.), Body Language - Communication (Vol. 38.2, pp. 1687-1702): de Gruyter. 
Ohta, A. S. 2001. Second Language Acquisition Processes in the Classroom: Learning Japanese. Manwah, NJ: Lawrence Erlbaum.

Olsher, D. 2004. Talk and gesture: The embodied completion of sequential actions in spoken interaction. In Gardner, R. and J. Wagner (eds.): Second Language Conversations (pp.221-245). London: Continuum International Publishing.

Petitjean, C. and E. González-Martínez. 2015. Laughing and smiling to manage trouble in French-language classroom interaction. Classroom Discourse 6 (2), 89-106.

Potter, J. and A. Hepburn 2010. Putting aspiration into words. 'Laugh particles', managing descriptive trouble and modulating action. Journal of Pragmatics 42(6), 1526-1542.

Smotrova, T. 2014. Instructional functions of speech and gesture in the L2 classroom. PhD Dissertation, The Pennsylvania State University.

Smotrova, T. 2015. Making pronunciation visible: Gesture in teaching pronunciation. TESOL Quarterly. doi: 10.1002/tesq.276

Smotrova, T. and Lantolf, J. 2013. The Function of Gesture in Lexically Focused L2 Instructional Conversations. The Modern Language Journal, 97 (2), pp. 397-416.

Stivers, T., Mondada, L., and Steensig, J. 2011. The Morality of Knowledge in Conversation, Cambridge: Cambridge University Press.

Streeck, J. 2009. Gesturecraft: The Manu-facture of Meaning. Amsterdam/Philadelphia: John Benjamins.

Stutzman, L. D. (2017). Multimodal Corrective Feedback and Interactional Moves within Language-Related Episodes and Inscription-Related Episodes: An Analysis. MA dissertation, University of Nottingham Ningbo China.

Swain, M. 1998. Focus on form through conscious reflection. In C. Doughty and J. Williams (Eds.), Focus on form in classroom second language acquisition (64-81). Cambridge: Cambridge University Press.

Swain, M. 2000. The output hypothesis and beyond: Mediating acquisition through collaborative dialogue. In J. Lantolf (Ed.), Sociocultural Theory and Second Language Learning (pp. 97-114). Oxford: Oxford University Press.

Swain, M. and S. Lapkin. 1998. Interaction and second language learning: Two adolescent French immersion students working together. The Modern Language Journal 82 (3): 320-337. 
Swain, M., Brooks, L., and A. Tocalli-Beller. 2002. Peer-peer dialogue as a means of second language learning. Annual Review of Applied Linguistics 22: 171-185.

van Compernolle, R. A., and T. Smotrova 2014. Corrective feedback, gesture, and mediation in classroom language learning. Language and Sociocultural Theory, 1, 25 47. 3

van Compernolle, R. A. and Williams, L. 2011. Thinking with your hands: Speechgesture activity during an L2 awareness-raising task. Language Awareness, 20, $203-$ 219. doi:10.1080/09658416.2011.559244

Williams, J. 1999. Learner-generated attention to form. Language Learning, 49(4), 583-625.

Williams, R. F. 2011. Coordinating and sharing gesture space in collaborative reasoning. Paper presented at the 3rd Conference of the Scandinavian Association for Language and Cognition, University of Copenhagen, Denmark, 14-16 June 2011. http://faculty.lawrence.edu/wp-content/uploads/sites/18/2015/11/GestureSpace-sl.pdf

Zeng, G. \& S. Takatsuka. 2009. Text-based peer-peer collaborative dialogue in a computer-mediated learning environment in the EFL context. System 37, 434-446. 
APPENDIX 1 - Transcription conventions

\section{Conventions for speech}

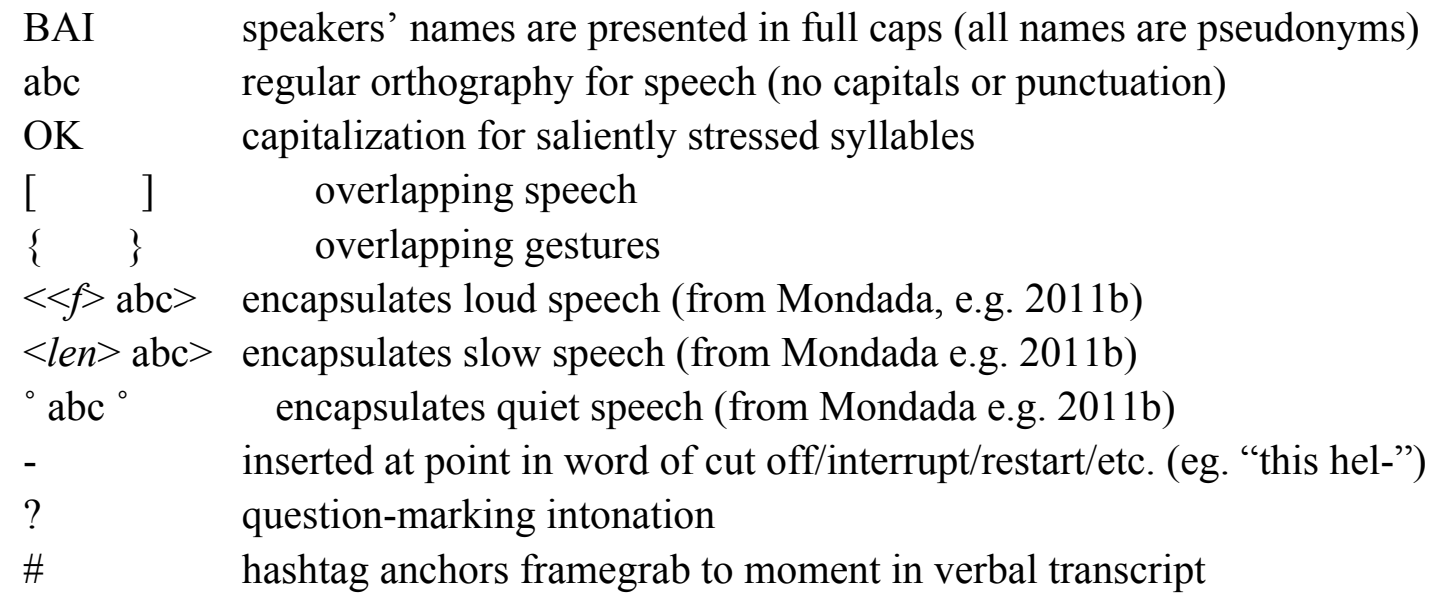

\section{Gesture phrase structure (Kendon 2004)}

\begin{tabular}{|c|c|}
\hline & start/end of gestural action \\
\hline$\sim \sim \sim$ & preparation phase \\
\hline$* * *$ & stroke phase \\
\hline -.--.- & retraction phase \\
\hline$* * * *$ & gestural action underlined is held \\
\hline$* / * *$ & the forward slash indicate a new stroke \\
\hline & gestural action described in italics (our addition) \\
\hline lh) & right hand/left hand, if two hands being used (our addition) \\
\hline & overlap i.e. people gesturing at the same time (ou \\
\hline
\end{tabular}

